NBER WORKING PAPER SERIES

\title{
ARE THE EFFECTS OF ADOPTION AND TERMINATION OF SHELTER-IN-PLACE ORDERS SYMMETRIC? EVIDENCE FROM A NATURAL EXPERIMENT
}

\author{
Dhaval M. Dave \\ Andrew I. Friedson \\ Kyutaro Matsuzawa \\ Drew McNichols \\ Joseph J. Sabia \\ Working Paper 27322 \\ http://www.nber.org/papers/w27322
}

\author{
NATIONAL BUREAU OF ECONOMIC RESEARCH \\ 1050 Massachusetts Avenue \\ Cambridge, MA 02138 \\ June 2020
}

Previously circulated as "Did the Wisconsin Supreme Court Restart a COVID-19 Epidemic? Evidence from a Natural Experiment." Sabia acknowledges research support from the Center for Health Economics \& Policy Studies (CHEPS) at San Diego State University, including grant support received from the Charles Koch Foundation and the Troesh Family Foundation. Dhaval Dave, Andrew Friedson, Kyutaro Matsuzawa and Drew McNichols declare that they have no relevant or material financial interests that relate to the research described in this paper. This study utilizes publicly available de-identified data and did not require IRB review. The data utilized in this study are publicly available. Additional data compiled from publicly available data sources and replication materials can be obtained from the authors. We thank Alicia Marquez for outstanding research assistance. The views expressed herein are those of the authors and do not necessarily reflect the views of the National Bureau of Economic Research.

NBER working papers are circulated for discussion and comment purposes. They have not been peer-reviewed or been subject to the review by the NBER Board of Directors that accompanies official NBER publications.

(C) 2020 by Dhaval M. Dave, Andrew I. Friedson, Kyutaro Matsuzawa, Drew McNichols, and Joseph J. Sabia. All rights reserved. Short sections of text, not to exceed two paragraphs, may be quoted without explicit permission provided that full credit, including $(\odot)$ notice, is given to the source. 
Are the Effects of Adoption and Termination of Shelter-in-Place Orders Symmetric? Evidence

from a Natural Experiment

Dhaval M. Dave, Andrew I. Friedson, Kyutaro Matsuzawa, Drew McNichols, and Joseph

J. Sabia

NBER Working Paper No. 27322

June 2020

JEL No. H75,I18

\section{ABSTRACT}

Policymakers have explicitly linked sustained reductions in COVID-19 case growth to reopening policies, including the lifting of shelter-in-place orders (SIPOs). This "hardwired" policy endogeneity creates challenges in isolating the causal effect of lifting a statewide SIPO on COVID-19. To overcome simultaneity bias, we exploit a unique natural experiment generated by the Wisconsin Supreme Court when it abolished Wisconsin's "Safer at Home" order on separation-of-powers grounds. We capitalize on this sudden, dramatic, and largely unanticipated termination of a statewide SIPO to estimate its effect on social distancing and COVID-19 case growth. First, using anonymized smartphone data from SafeGraph Inc. and a synthetic control design, we find that SIPO termination had little impact on social distancing. Then, using data on COVID-19 case and mortality rates, we find no evidence that the Wisconsin Supreme Court decision impacted COVID-19 growth up to a month following the repeal. We conclude that the impacts of SIPOs are likely not symmetric across enactment and lifting of orders, and this asymmetry sheds new light on the potential mechanisms underlying the effectiveness of these orders.

Dhaval M. Dave

Bentley University

Department of Economics

175 Forest Street, AAC 195

Waltham, MA 02452-4705

and IZA

and also NBER

ddave@bentley.edu

Andrew I. Friedson

Department of Economics

University of Colorado Denver

Lawrence Street Center 460T

Campus Box 181

P.O. Box 173364

Denver, CO 80217-3364

andrew.friedson@ucdenver.edu
Drew McNichols

San Diego State University

Center for Health Economics

$\&$ Policy Studies

5500 Campanile Drive

San Diego, CA 92182

dmcnichols@ucsd.edu

Joseph J. Sabia

San Diego State University

Department of Economics

Center for Health Economics

$\&$ Policy Studies

5500 Campanile Drive

San Diego, CA 92182

and IZA \& ESSPRI

jsabia@sdsu.edu

Kyutaro Matsuzawa

Center for Health Economics and Policy Studies

San Diego State University

San Diego, CA

qmatsuzawa@gmail.com 


\section{Motivation}

The speed and breadth with which COVID-19-related government restrictions on business operations, personal movements, and assembly rights should be lifted has sparked an intense public policy debate (Jarvie 2020, Vainshtein 2020). Proponents of lifting nonpharmaceutical interventions (NPIs) such as blanket shelter-in-place orders (SIPOs) ${ }^{1}$, nonessential business closings, bans on large gatherings, and school closings argue that the costs of these policies — including increased unemployment (Baek et al. 2020, Couch, Fairlie and Xu 2020), decreased human capital acquisition (Doyle 2020), diminished consumption of preventative and emergency care (Lazzerini et al. 2020, Santioli et al. 2020), and poorer psychological health (Galea, Merchant and Lurie 2020, Hsing et al. 2020) — may be substantial. Opponents argue that a rapid, broad-based reopening would quickly reduce social distancing, create a false sense of optimism about contagion, and reignite the coronavirus pandemic, overwhelming hospital resources (i.e. ventilators, hospital beds, and medical professionals) and increasing coronavirus-related deaths. These arguments have framed the political debate over the efficacy of lifting SIPOs and reopening non-essential businesses (Colliver 2020, Fadel 2020, Usero 2020).

However, it is also possible that lifting SIPOs may have much smaller effects on social distancing, COVID-19 cases, and unemployment rates than both proponents and opponents suggest. If most social distancing behavior and job loss are not caused by the restrictions imposed by the mitigation policies per se, but rather are explained by demand shocks caused by rapid diffusion of COVID-19 information or via Bayesian updating of coronavirus risk

\footnotetext{
${ }^{1}$ Individuals under a SIPO are only allowed to leave their homes for “essential” activities such as shopping for food or medicine, reporting for work in an industry deemed essential, or caring for a sick relative.
} 
assessment (Barrios and Hochberg 2020, Holtz et al. 2020), the effects of lifting SIPOs may be quite small. ${ }^{2}$ Moreover, the elasticity of social distancing (and COVID-19 cases) with respect to mitigation policies may fall over time as individuals learn about healthier options for population mixing (i.e. mask-wearing, 6-feet social distancing with non-household members). ${ }^{3}$

Using a standard difference-in-differences approach to estimate the effect of lifting a statewide SIPO on COVID-19 cases faces two first-order identification problems. First, policymakers explicitly tie the decision to allow a SIPO to expire to COVID-19 case growth, a textbook case of policy endogeneity. White House reopening guidelines, issued jointly with the Centers for Disease Control and Prevention recommend a "downward trajectory of documented cases within a 14-day period" before a state or region proceeds to a phased reopening (White House 2020; Centers for Disease Control and Prevention 2020). This national recommendation is in-line with state and local policies with regards to ending SIPOs. ${ }^{4}$ For instance, Oregon rules require that "counties where more than 5 people have been hospitalized for severe COVID-19 symptoms in the past 28 days must see declining hospitalizations for 14 days in order to begin reopening” (Oregon Health Authority 2020). Similarly, New York requires “a downward trajectory of hospitalizations and infections over a 14-day period," as well as "a sustained decline in the three-day rolling average of daily hospital deaths over the course of a 14-day period,” which like the national recommendations explicitly links trends in the outcome variable of interest to implementation of the policy (New York Forward 2020).

\footnotetext{
${ }^{2}$ It is also possible that SIPO adoption or lifting may impact perceptions of coronavirus risk as well as information about the virus's spread.

${ }^{3}$ This argument suggests that the social distancing (and case) effects of SIPO adoption and SIPO lifting may be asymmetric.

${ }^{4}$ While the federal government can make recommendations with regards to social distancing policies, the power to enact or revoke most of these policies lies with state and local governments.
} 
These ties of policy to trend are not simply made explicit in the written policies, but are also publicly communicated by state leadership. To take one prominent example, in a May 22, 2020 news conference, New York governor Andrew Cuomo commented on reopening plans for the Mid-Hudson region (immediately north of New York City) as well as parts of Long Island, saying, "If the number of deaths continue to decline ... both regions could reopen" (Newsday Staff 2020).

Second, an emerging literature documents that the enactment of statewide SIPOs, particularly those that were adopted early and in areas with low case growth (Friedson et al. 2020; Dave et al. 2020a, b) were successful at "bending the case curve” for COVID-19 (Courtemanche et al. 2020a,b; Dave et al. 2020a). For instance, Dave et al. (2020a) find that SIPO adoption is associated with a 53.5 percent reduction in COVID-19 cases. Taken at face value, these results imply that pre-treatment trends in a difference-in-differences-based statewide SIPO expiration analysis will not be parallel. ${ }^{5}$

Together, the above insights suggest that using a difference-in-differences approach to estimate the impacts of SIPO expiration will be highly problematic for causal inference. ${ }^{6,7}$ Thus, rather than examine gubernatorial decisions on SIPO lifting, we instead turn to a unique natural experiment to identify the causal effect of SIPO expiration on social distancing and COVID-19

\footnotetext{
${ }^{5}$ This would be true among early adopting SIPO states, which were the only states for which SIPOs were found to "bend the case curve".

${ }^{6}$ We hypothesize that the expiration of a SIPO is much more endogenous to COVID-19 cases than was its enactment. No state or Federal guidelines of which we were aware recommended jurisdictions enact a SIPO if a case growth rate rose above a particular threshold.

${ }^{7}$ Note that there is no problem of insufficient policy variation, just that the available variation is likely to be endogenous in most cases. There is a considerable amount of variation in the timing of the end of state or local SIPO, with 37 states lifting some form of social distancing policy between April 20, 2020 and May 13, 2020. However, policies regarding coronavirus provide numerous challenges to the difference-in-differences strategy, in particular with regards to the assumption of parallel pre-policy trends (Goodman-Bacon and Marcus 2020), concerns that are exacerbated in the context of examining reopening states by ending social distancing policies as both national guidance and explicit state level policy rules tie opening behaviors to the trends themselves.
} 
cases. This sudden, dramatic, and somewhat unexpected policy shock was generated by a state court ruling on the constitutionality of a statewide SIPO.

On May 13, 2020 in Wisconsin Legislature v. Palm, the Wisconsin State Supreme Court struck down Wisconsin’s “Safer at Home Order” (Ruthhart 2020). The Court ruled that Andrea Palm, the secretary-designee of the Wisconsin Department of Health Services, violated state law by issuing the stay-at-home decree as an "order" instead of a "rule." This distinction allowed the Executive Branch (the governor's office) to circumvent weeks-long legislative oversight and possible veto, and instead immediately implement the policy (Supreme Court of Wisconsin 2020). While Palm argued that the specificity of the COVID-19 crisis permitted her to issue an order, the Court ruled that by bypassing a lengthy administrative rulemaking process and legislative review (Johnson 2020; Millhiser 2020), the Safer at Home Order was “unlawful, invalid, and unenforceable” (Vetterkind and Schmidt 2020; Hagemann 2020).

The force and effect of this legal ruling was dramatic and immediate. The entire statewide order was overturned (with the exception of the school closures; see Deliso 2020; Beck 2020), making Wisconsin the only U.S. state without a single statewide protective measure in place (Ruthhart 2020). ${ }^{8}$ The legal ruling immediately allowed non-essential businesses to reopen without restriction, with many bars opening on the night of the decision, gaining national media attention (O’Kane 2020). Observing the night’s events, Wisconsin’s Governor Tony Evers said that the ruling had "throw[n] the state into chaos," and predicted that "people are going to get sick” (Evers 2020).

\footnotetext{
${ }^{8}$ This decision also marked the first successful legal challenge of a SIPO (Deliso 2020; Beck 2020; Jimenez and LeBlanc 2020).
} 
This study exploits this unique experiment to identify the causal effect of Wisconsin's SIPO termination on social distancing and COVID-19 cases. First, using anonymized, geospatial smartphone data from SafeGraph, Inc. from May 3 through June 2, and a synthetic control approach, we find no evidence that the statewide legal order significantly affected net stay-athome behavior as measured by the percent of time spent at home full-time (extensive margin) and median hours spent at home (intensive margin). ${ }^{9}$ Our analyses of "point of interest” data do, however, suggest some evidence that foot traffic at restaurants and bars rose following the Supreme Court decision.

Then, turning to data on COVID-19 cases and deaths collected by the New York Times from May 3 through June 12, synthetic control estimates fail to detect any evidence that the Wisconsin Supreme Court order affected COVID-19 cases up to a month following the state's SIPO repeal. This post-treatment period (i) exceeds the incubation period of COVID-19 (Lauer et al. 2020) and (ii) represents a window during which studies of policy shocks or non-household gatherings have detected substantial changes in COVID-19 spread (Mangrum and Niekamp 2020; Dave et al. 2020a,b,c; Friedson et al. 2020; Courtemanche et al. 2020a, b). Our null results are robust to the choice of donor states and to matching variables used to create synthetic weights, including COVID-19 case rates per 100,000 population on all pre-treatment days, urbanicity rate, population density, COVID-19 testing rates, pre-treatment social distancing, and other business reopening policies.

The remainder of the paper explores the explanation for this null result and explores whether our finding masks important heterogeneity in treatment effects. We draw four

\footnotetext{
${ }^{9}$ Goodman-Bacon and Marcus (2020) recommend that in the context of COVID-19 policies, researchers focus especially on techniques "that impose balance in pre-policy infection levels and trends," such as synthetic control.
} 
conclusions from this analysis. First, our results cannot be explained by the ineffectiveness of the initial adoption of Wisconsin's SIPO. To the contrary, we find that the enactment of WI's SIPO — which occurred very early in the outbreak cycle and was, therefore, likely enacted exogenously to local COVID-19 conditions (Friedson et al. 2020) — had a strong negative effect on COVID-19 case growth. Thus, the COVID-19 spread effects of SIPO adoption and repeal in Wisconsin were, in fact, asymmetric. Second, while 5 of 72 Wisconsin counties enacted longerterm local safer-at-home orders to try to counter the Supreme Court decision, accounting for these county policies does not change our main findings. Third, we find no evidence that urbanized or densely populated counties were differentially affected by SIPO termination. Moreover, we find no evidence that COVID-19 cases grew more quickly in counties experiencing the largest increases in foot traffic at restaurants and bars following the SIPO repeal. Finally, while we do find that the termination of the SIPO was associated with a larger short-run decline in social distancing in counties with higher proportions of Donald Trump voters, there is little evidence that post-repeal COVID-19 cases grew more rapidly in these counties. In summary, there is very little evidence that the termination of Wisconsin's SIPO had deleterious effects on COVID-19 spread in the state.

The findings from this study make important contributions to the literature on NPIs along several dimensions. First, we find strong evidence that the impact of rolling out a SIPO may be asymmetric to the impact of pulling one away. There are several possible reasons for this finding. Most SIPOs, including Wisconsin’s SIPO, were adopted at a time where information about the virus - including information about which behavioral countermeasures were most effective at reducing exposure — was still being refined and disseminated. As such, the behavioral response to and health benefits from SIPO enactment may have been quite different 
than those from SIPO removal, as new health behaviors may have been learned by the time the SIPO was repealed.

Relatedly, during SIPO enactment, the implementation of legal restrictions was likely packaged together with an information shock on the seriousness of the illness, causing individuals to update their risk perceptions and change their behavior. ${ }^{10}$ When the Wisconsin Legislature v. Palm decision took effect, there was relatively little accompanying new information about the severity of the virus, meaning that individual behavioral changes would largely be due to the change in legal restrictions alone. Thus, our findings suggest that the mechanism of information may be particularly important in understanding asymmetry in the health effects of SIPO adoption and repeal.

\section{Background on and Reaction to Wisconsin Supreme Court Decision}

Wisconsin saw its first case of COVID-19 on February 5, 2020 (Wisconsin Department of Health Services 2020; Wiscontext 2020). More than a month passed before the second documented case emerged on March 9. By March 25, there were 583 new confirmed cases, bringing the total number of cases to 585 or 10 cases per 100,000 population (Wisconsin Department of Health Services, 2020; Wiscontext, 2020). In an attempt to “flatten the case curve,” at 8:00 a.m. on Wednesday, March 25, 2020, Andrea Palm, secretary-designee of the Wisconsin Department of Health Services (under the direction of Governor Tony Evers) signed Emergency Order 12, a statewide “Safer at Home Order” (State of Wisconsin 2020).

\footnotetext{
${ }^{10}$ Whether such updating led to socially optimal updating of risk preferences depends on the extent to which the policy's “information shock” corrected underestimation of risk while not overinflating individuals' assessment of true risks of contagion or serious adverse health conditions.
} 
This SIPO required all individuals within the state of Wisconsin to stay in their place of residence at all times except for essential activities. Essential activities were defined as those activities necessary to maintain health and safety, such as obtaining medication or seeking emergency health care, grocery shopping, outdoor exercise, performing work at essential businesses or operations and related travel, and provision of care for others (State of Wisconsin 2020). Additionally, the SIPO required social distancing of six feet whenever residents left their houses, and prohibited all non-essential travel. The order also required all non-essential business operations to cease, performing only Minimum Basic Operations (State of Wisconsin 2020). ${ }^{11}$ Exempt from this order were businesses deemed essential, including but not limited to stores that sell food and medicine, transportation, funeral establishments, take-out services, transportation, and social service organizations (State of Wisconsin 2020).

This order was set to remain in effect until 8:00 a.m. on Friday, April 24, 2020. However, eight (8) days prior to the expiration date, Andrea Palm issued Emergency Order 28, which extended the Safer at Home order until 8:00 a.m. on Tuesday, May 26, 2020 (Office of the Governor 2020). The order also implemented changes to the original order, which were to be effective on April 24. Included in these changes were modest re-openings for non-essential businesses. Public libraries were allowed to open for curbside pick-up, golf courses were permitted to open with restrictions to ensure social distancing, in-person retail was allowed for up to five customers at a time at particular shops, arts and craft stores were allowed to offer curbside pick-up, and aesthetic work was permitted with one worker (State of Wisconsin 2020; Office of the Governor 2020). In addition, guidelines for safe business practices, including

\footnotetext{
${ }^{11}$ These include the necessary activities to maintain the value of the inventory and capital, process payroll, facilitate remote work, and other related functions.
} 
disinfecting practices and safe waiting areas or lines were also announced. Finally, all public and private schools were ordered to remain closed for the remainder of the school year.

The revised Safer at Home order was set to expire on May 26. But on April 21, the Republican-controlled Assembly and Senate, led by Senate Majority Leader Scott Fitzgerald and Assembly Speaker Robin Vos, filed a lawsuit, Wisconsin Legislature v. Palm, which sought to overturn the Safer at Home order on separation of powers grounds (Wisconsin Legislature v. Palm 2020; Millhiser 2020). While state law allows the Department of Health Services extensive power when dealing with a communicable disease, the Republican legislature claimed that the Office of the Secretary had exceeded its legal authority. In a 4 to 3 decision, issued on March 13, 2020, the Wisconsin State Supreme Court struck down the statewide SIPO, siding with the plaintiffs that the administration had exceeded its authority (Ruthhart 2020; Vetterkind and Schmidt 2020; Deliso 2020; Beck 2020; Jimenez and LeBlanc 2020; Hagemann 2020). In addition to striking down the SIPO, the order declared all new COVID-19 public health restrictions in Wisconsin subject to review and potential veto by legislative committee.

Political opinion in Wisconsin was divided. While Republican Senate Majority Leader Fitzgerald said that “the public started to become skeptical” of Democrat Governor Evers’ ability to guide the state through the pandemic (Beck 2020), polls taken during the week the Supreme Court decision was handed down showed that the public trusted Evers with reopening of the state more than the state legislature. Additionally, polls found that nearly 70 percent of voters believed that Evers' order was appropriate given the severity of the pandemic (Ruthhart 2020; Beck 2020). ${ }^{12}$

\footnotetext{
${ }^{12}$ During the decision process, dissenting justice Ann Bradley stated that "the lack of a stay would be particularly breathtaking given the testimony yesterday before Congress by one of our nation's top infectious disease experts, Dr. Anthony Fauci. He warned against lifting too quickly stay-at-home orders” (Ruthhart 2020).
} 
Reaction to the Supreme Court decision was swift and partisan. Governor Tony Evers declared:

“Republican legislators convinced four members of the Supreme Court to throw the state into chaos. They have no plan. People are going to get sick, and those Republicans own this chaos” (Ruthhart 2020).

whereas Republican Steve Nass, co-chairman of the Wisconsin legislature's rules committee claimed:

"I have great faith that people will make the decisions necessary to fight COVID-19 on their own without excessive government intervention” (Richmond 2020).

Of course, the actual response by individuals within Wisconsin remains an empirical question, and is the focus of the analyses to follow.

\section{Data}

To examine the effect of the Wisconsin Supreme Court decision on social distancing, we utilize an anonymized population movement dataset representing approximately 45 million smartphone devices from SafeGraph Inc. ${ }^{13}$ Data are aggregated to the census block level and made available publicly. These data have been used by a growing number of scholars studying

\footnotetext{
${ }^{13}$ Data and detailed descriptions are available at: https://www.safegraph.com/dashboard/covid19-shelter-in-place
} 
social distancing and the COVID-19 outbreak (Andersen et al. 2020; Dave et al. 2020a,b,c,d; Friedson et al. 2020; Abouk and Heydari 2020; Lasry et al. 2020). Our analysis period spans May 3, 2020 through June 2, 2020, with a starting date that ensures that our results are not confounded by the modest re-openings of non-essential businesses that began on April $24^{\text {th }}$ with the extension of the original SIPO, or by the April $7^{\text {th }}$ Wisconsin Primary (Cotti et al. 2020).

We proxy for various dimensions of social distancing using the Social Distancing Metrics (SDM) and Points-of-Interest (POI) data derived from SafeGraph. In the SDM, the base unit of observation is the cellphone, with each device assigned a "home" based on a common nighttime location. ${ }^{14}$ We construct two measures at the daily level, capturing the percent of cellphones within an area (state or county) that remained at home for the entire day, and the median number of hours that a cellphone spent within the home location on a given day. The former measure captures "strong" social distancing, and the latter measure captures social distancing behavior at the intensive margin. Both measures have been found to be significantly affected by the imposition of shelter-in-place orders (Dave et al. 2020a,b; Friedson et al. 2020; Cronin and Evans 2020), though it remains to be determined if the effects are symmetric when these orders are lifted. About $34.6 \%$ of sampled cellphones in Wisconsin remained at home full-time over the sample period, and sampled cellphones remained in their homes for a median number of 11.7 hours per day.

In order to capture mobility and foot-traffic patterns, we turn to the POI data, wherein the base unit of observation is a "point of interest", often a business establishment. Each establishment is identified with a location and type (using six-digit North American Industry

\footnotetext{
${ }^{14}$ The "home" location is defined as a 153-meter by 153-meter location where the cellphone pinged most frequently during the hours between $6 \mathrm{pm}$ and 7am over a 6-week baseline period.
} 
Classification System industry codes), and we observe the number of distinct cellphone pings at that establishment each day. We aggregate these data across business types, focusing largely on restaurants and bars as well as retail services, and construct a measure of the count of pings at each business type in a given area on each day. ${ }^{15}$ These variables provide information on the types of activities that may be impacted by shelter-in-place restrictions, and whether a repeal of the SIPO resumed foot-traffic at these locations.

We next utilize a panel of state-specific (and, in alternate models, county-specific) daily counts of reported cases and deaths from May 3, 2020 through June 12, 2020, a period that envelopes the SIPO repeal by 10 days prior to and up to a month subsequent to the repeal. These data are compiled by The New York Times based on reports from state and local health agencies. ${ }^{16}$ As of June 12, there were a total of 2,052,109 confirmed COVID-19 cases in the United States, $1.1 \%(22,345)$ of which were in Wisconsin, and 114,528 coronavirus-related deaths, $0.6 \%$ (692) of which were in Wisconsin. Our central public health outcome of interest is Case Rate $_{\text {st }}$, measuring the cumulative number of confirmed coronavirus cases per 100,000 population in state $s$ at day $t^{17}$

\section{Methods}

To identify the effects of the termination of the statewide shelter-in-place order on social distancing and public health we capitalize on the unanticipated policy shock, generated by the

\footnotetext{
${ }^{15}$ In supplemental analyses, we also examine foot traffic at entertainment venues and business services establishments.

${ }^{16}$ These data can be obtained here: https://github.com/nytimes/covid-19-data

${ }^{17}$ Appendix Figure 1 shows state-specific trends in cumulative coronavirus case and death rates in Wisconsin as well as for the remaining 49 states and DC. We also explore effects on the Death Rate ${ }_{s t}$, which is the cumulative number of COVID-19-related deaths in state $s$ on day $t$.
} 
Wisconsin State Supreme Court's ruling. We utilize the synthetic control method introduced by Abadie et al. (2010) which relies on data from pre-treatment outcomes and observable characteristics of states that may influence the spread of the virus (or its detection) to generate a counterfactual for Wisconsin.

To generate this counterfactual in the absence of the Supreme Court decision, we draw on a donor pool of states that had a statewide SIPO in place during the entire analysis period, and states that allowed their SIPOs to expire but had a post-expiration window that did not exceed the incubation window for COVID-19 (Lauer et al. 2020). ${ }^{18}$ Our main analysis period covers May 3 through June 2, spanning three weeks post-repeal, a window sufficiently long enough to pick up any substantial effects on COVID-19 infections if there are any such effects. Our primary donor pool comprises of 17 states and the District of Columbia (DC). In supplementary analyses, we further extend the post-repeal window to a full month (through June 12) to ensure that sufficient time is allowed for differential COVID-19 growth to materialize. To conduct this analysis, we must exclude 4 states from the original donor pool (District of Columbia, Illinois, Ohio, and North Carolina) to avoid contaminating the control group.

Given the importance of our selection of (i) states to be included in the donor pool, and (ii) observable characteristics on which to closely match Wisconsin to its synthetic counterpart, we explore the sensitivity of our estimates to these choices (Ferman 2019). With regard to the choice of observables used to select our synthetic control from among donor states, we take several approaches. In our first strategy, we match on the outcome (stay-at-home behavior, foot

\footnotetext{
${ }^{18}$ About 97.5 percent of infected individuals who develop symptoms are found to do so within 11-12 days (Lauer et al. 2020). Hence, allowing for this lag from the incubation window, prior work has uncovered that SIPOs generally have the strongest impact in reducing COVID-19 cases after about 10-14 days following adoption (Dave et al. (2020 $\mathrm{a}$; b). A state is permitted to have at most 11 days of post-SIPO expiration data in order to qualify for our main donor pool.
} 
traffic, and COVID-19 case rates) on each of the 10 pre-treatment days (May 3 through May 12), which effectively requires growth rates to be identical. Choosing a counterfactual based only on pre-treatment outcomes eliminates concerns of 'p-hacking' (Hansen et al. 2020; Botosaru and Ferman 2017). However, this approach also effectively eliminates the role of other factors that could affect COVID-19 outbreak (Kaul et al. 2018). ${ }^{19}$

In light of this, we also construct our synthetic counterfactual by alternately giving a larger role to the predictors and drivers of the outbreak, and match on (i) COVID-19 testing rates, which may play an important role in coronavirus detection, (ii) other pre-treatment COVID-19 policies (i.e. whether the state permitted state parks to be open and whether it permitted roadside pickup of retail, both of which Wisconsin had prior to the Supreme Court decision), (iii) percent of the state that voted for the Republican presidential candidate in 2016, given that political preferences have been found to correlate with social distancing orders and engagement in mitigation strategies (Barrios and Hochberg 2020), (iv) state population density and urbanicity, factors that promote individual interactions and hence play an important role in COVID-19 spread, and (v) social distancing prior to the Supreme Court Decision.

Across each of our matching strategies, we assess statistical significance using permutation-based p-values. Specifically, we conduct placebo tests on each of the donor states following the method suggested by Abadie et al. (2010) to generate permutation-based p-values. Next, we carry over the control states identified in the synthetic control approach and estimate the following difference-in-differences specification, drawing upon county-by-day data:

\footnotetext{
${ }^{19}$ As shown by Kaul et al. (2018), matching on all periods of pre-treatment outcomes renders all covariates irrelevant in the prediction of the outcome.
} 


$$
\mathrm{Y}_{\mathrm{cst}}=\beta_{0}+\beta_{1} * \operatorname{SIPOEXP}_{\mathrm{cst}}+\mathrm{Z}_{\mathrm{st}} * \Omega+\alpha_{\mathrm{cs}}+\gamma_{\mathrm{t}}+\varepsilon_{\mathrm{cst}}
$$

where $\mathrm{Y}_{\mathrm{cst}}$ measures one of our outcome variables (stay-at-home behavior, log foot traffic, log COVID-19 cases) in county $c$ in state $s$ on day $t$, and SIPOEXP is an indicator set equal to 1 if the observation is drawn from Wisconsin in the post-Supreme Court repeal period. The sample is comprised of counties in Wisconsin and in each of the donor states from the synthetic control analysis. The vector $Z_{\text {st }}$ includes indicators for whether the state had begun a partial reopening of restaurants, bars, and retail stores (i.e. roadside pick-up, limited capacity), a partial reopening of personal/pet care, including barber, salons, and pet-grooming services, and a partial reopening of activities and entertainment including gyms, state parks, and drive-in theatres. We also include the log of the daily testing rate in order to ensure that estimates are not confounded by differential testing capabilities across states. In addition, $\alpha_{c}$ is a set of county fixed effects to control for fixed differences across counties (and states) in social distancing or COVID-19 infections due to, for example, baseline hospital capacity differences, population density, or baseline testing capacity; $\gamma_{\mathrm{t}}$ is a set of day fixed effects. ${ }^{20}$ Regressions are weighted using county population-adjusted synthetic weights. ${ }^{21}$

In alternate specifications, we add controls for state-specific linear time trends $\left(\alpha_{s} * t\right)$ to capture any unmeasured state trends that could be coincidental with COVID-19 growth and the Supreme Court decision. Locality-specific trends can help account for unobserved factors

\footnotetext{
${ }^{20}$ Day fixed effects also flexibly control for any intra-week cyclical variation (i.e., weekday vs. weekend or holiday effects) that may be driving the demands for time, economic/non-economic activity, and social distancing. ${ }^{21} \mathrm{All}$ states in the donor pool are included in the difference-in-differences analyses. We assign an arbitrarily small weight of 0.001 to those donor states that received a zero weight in the synthetic control estimation, and normalize the other positive synthetic weights to compensate. Expectedly, this has virtually no impact on our estimated treatment effects. Our primary motivation for including all of the donor states in the difference-in-differences estimation is to be able to draw on our full donor pool when we conduct the permutation-based statistical inference (described below) and be able to generate a sufficient number of placebo treatment effects for the rank test.
} 
driving the exponential growth trajectory of transmissions, and effects in this case would be identified off deviations from trend growth (Dave et al. 2020a).

The chief advantage of the county-by-day difference-in-differences model is that it allows us to explore heterogeneity in the effect of the Wisconsin Supreme Court decision across several margins, as follows:

$$
\mathrm{Y}_{\mathrm{cst}}=\beta_{0}+\left(\operatorname{SIPOEXP} \mathrm{cst} * \mathrm{X}_{\mathrm{c}}\right) * \Pi+\mathrm{Z}_{\mathrm{st}} * \Omega+\alpha_{\mathrm{cs}}+\gamma_{\mathrm{t}}+\varepsilon_{\mathrm{cst}}
$$

where $X_{c}$ denotes the specific dimension that may drive potential differential responses in Wisconsin to the Supreme Court's rescinding of the statewide SIPO.

First, we consider whether the county issued a local stay-at-home order in response to the statewide termination. Fourteen of the state's 72 counties responded to the Supreme Court ruling by enacting policies to mitigate the potential effects of the lifting of the SIPO. Extenders include population centers (such as the cities of Madison and Milwaukee) as well as several less urban counties. These localities effectively extended the governor's shelter-in-place order by reissuing local public health orders, and conveying to residents and businesses that a local order remains in effect in spite of the statewide order being overturned. For most of these localities, the extensions and stays were temporary, on average lasting only three to four days beyond the Supreme Court ruling, and enacted mainly as a stop-gap measure to give businesses time to prepare to reopen. Five counties, representing $30.9 \%$ of the state's population, however 
prolonged their local stay-at-home orders longer with residents in these counties bound by their local SIPOs for at least two weeks following the Supreme Court decision. ${ }^{22}$

While the Supreme Court ruling was binding for most Wisconsinites, we assess whether there were any differential effects in social distancing and COVID-19 cases across counties that strictly abided by the ruling and its timing vs. counties that responded by extending their local orders either temporarily or for a protracted period. We estimate equation (2) by interacting an indicator $\left(X_{c}\right)$ for whether the county issued an extension in response to revocation of the statewide SIPO.

Next, we explore heterogeneity in the effects of the repeal of the SIPO by urbanicity and population density, by alternately interacting the SIPO repeal with whether the county had an urbanicity rate of at least $50 \%\left(X_{c} ; 26\right.$ of all 72 Wisconsin counties). Prior work has established that state as well as localized SIPOs are more effective in states and counties that are highly urbanized and densely populated (Dave et al. 2020a,b). These studies find that shelter-in-place orders elicit a larger response vis-a-vis social distancing in more urban and populated areas, and also that a given level of social distancing may translate into larger gains in the containment of COVID-19 infection in these areas.

Finally, we consider whether the effects of the Supreme Court decision differed based on political preferences, by interacting the main effect in equation (2) with an indicator for whether a majority of the county voted for Republican presidential candidate Donald Trump in 2016. Given the divided political opinion in the state, and the split decision across party lines, ideology

\footnotetext{
${ }^{22}$ These five counties are: Dane (superseded on June 5), Eau Claire (expired on May 28), Florence, Milwaukee (the City of Milwaukee continued its SIPO through at least May 27), and Racine (expired May 26). The other nine counties with temporary stays are: Kenosha, Calumet, Outagamie, Winnebago, and Brown, with extensions of local orders ranging from 1-3 days; and Marquette, Green, Door, and Rock, with extensions from 5-9 days.
} 
may well impact the degree to which residents heeded the Democratic governor's admonition to continue sheltering-in-place after the repeal of the statewide SIPO.

For the difference-in-differences analyses, with a single treated state and few control states, deriving inferential statistics based on state-clustered standard errors is not an option as these would likely overestimate statistical significance (Cameron and Miller 2015). We therefore conduct statistical inference via permutation-based p-values generated by rank tests, which imposes a very high standard for achieving statistical significance (Cunningham and Shah 2018). This involves comparing our treatment effect generated from the difference-indifferences model with placebo estimates obtained by running additional specifications, in each case replacing Wisconsin (the true treated unit) with one of the other control states. Because Wisconsin and the 18 donor states comprise a total of 19 jurisdictions, achieving $5 \%$ significance is not possible in our case. For instance, if the total number of states (Wisconsin plus donor states) in a given difference-in-differences model is 19 , then achieving at best $5.3 \%$ significance requires that Wisconsin be ranked at the very extreme of the placebo distribution. We present these rank tests for all estimates, and draw conclusions from the weight of the evidence from the magnitudes, consistent patterns, and inferential statistics.

\section{Results}

\subsection{Wisconsin’s SIPO Repeal and Social Distancing}

Figures 1 and 2 present trends in the various measures of stay-at-home behavior and foot traffic for both Wisconsin and its synthetic control. We visually present trends based on two alternate sets of synthetic controls, one that assigns weights based on close matches on the social distancing outcome on each of the 10 pre-repeal days, and one that matches with respect to the 
social distancing outcome on each of five days in the pre-repeal period (May 4, 6, 8, 10, 12)

along with all of the observed predictors of the outbreak. These constructed synthetic controls serve as our counterfactual for trends in social distancing that would have unfolded in the absence of Wisconsin’s Supreme Court decision.

Figure 1, Panels (a) and (b), plot Wisconsin and synthetic Wisconsin for the percent of respondents staying at home full-time throughout the day, and Panels (c) and (d) repeat this exercise for median hours spent at home, which captures the intensive margin of stay-at-home behavior. These analyses highlight three key points. First, trends in staying-at-home behaviors in Wisconsin and synthetic Wisconsin are nearly identical in the pre-repeal period. Even when we do not force matches on the outcome across all pre-treatment days (Panels b and d), the synthetically generated counterfactual tracks the actual trends in Wisconsin very well in the prerepeal periods. Second, there is a slight decline in social distancing throughout the sample period for both Wisconsin and its synthetic control, with some intra-week variance. Third, there is little evidence of any substantial trend break or sustained decrease in sheltering-in-place in Wisconsin, relative to synthetic Wisconsin, after the statewide repeal. There is some suggestive indication of dynamics in the very short-run, with the percent staying at home full-time in Wisconsin declining by May $15^{\text {th }}$ (Friday) relative to the control; the magnitude of the effect is about 1.3 percentage points (3.5\% relative to the baseline mean in the state). Taking somewhat longer, by May $23^{\text {rd }}$ (Saturday), median hours spent at home also exhibits some decline, of about 0.94 hours (7.3\% relative to the baseline mean). ${ }^{23}$ However, sheltering-in-place then rebounds over the next

\footnotetext{
${ }^{23}$ Appendix Figure 2 presents the placebo tests for each of the social distancing and mobility measures. The shortterm dynamics in sheltering-at-home are more apparent here (Panels a and b) when contrasted against the placebo effects. The decline in the percent staying at home and time spent at home within 3 days (10 days) post-repeal have one-sided, one-tailed permutation based p-values of 0.211 and 0.211 (0.316 and 0.158), respectively.
} 
few days, with little discernible difference between treated Wisconsin and its synthetic control by the end of the analysis period.

Figure 2 depicts corollary trends in foot-traffic at restaurants and bars (Panels a and b) and at retail establishments (Panels c and d) for Wisconsin and its counterfactual. While we do not find any strong or sustained decrease in stay-at-home behaviors from the SIPO repeal, the legal ruling did immediately allow non-essential businesses such as restaurants, bars and various retail venues to reopen without any restrictions, in which case analyses of mobility patterns at these venues may be better equipped to identify more immediate or persistent impacts of the lifting of the SIPO. There is some suggestive evidence of a lagged increase in foot-traffic at bars and restaurants after 10-14 days following the repeal, mainly falling on Fridays through Sundays. ${ }^{24}$ However, there is little visual evidence to indicate that any such increase in foottraffic at bars and restaurants or retail venues in Wisconsin, relative to the synthetic control, was sustained or substantial.

In Table 1, we report estimates of the average daily effect of the repeal of the state's SIPO on each of the social distancing measures. ${ }^{25}$ Column (1) presents estimates of the average treatment effect over the post-repeal period, comparing Wisconsin to its synthetic control, where the synthetic control is formed by matching on the outcome on each of the 10 days preceding the Supreme Court decision (as presented in panels a and c in Figures 1 and 2). The remaining columns in Table 1 limit the pre-treatment social distancing matches to (alternating) 5 days and allow a larger role for observable predictors of the outbreak in the matching process. ${ }^{26}$ The last

\footnotetext{
${ }^{24}$ This lag in foot-traffic at bars and restaurants, and the similar short-lived lag in median hours spent at home, may reflect both a behavioral lag as well as any lag between the SIPO repeal and business reopenings.

${ }^{25}$ Appendix Table 1 reports the donor states receiving positive weights for each analysis in Table 1.

${ }^{26}$ Our primary donor pool consists of states that have SIPOs in place during the entire analysis period, and states whose SIPOs expired with less than 12 days of data since their expiration, thus maintaining a sufficient temporal
} 
column presents estimates when all of the observable predictors of social distancing are used for matching (as presented in panels $\mathrm{b}$ and $\mathrm{d}$ in Figures 1 and 2).

Finally, given that Wisconsin’s overturning of its statewide SIPO was an unanticipated and abrupt policy shock as a result of the state Supreme Court decision, we are less concerned with policy endogeneity. Nevertheless, we also explicitly add pre-treatment COVID-19 cases to our set of observable predictors in the matching process, which makes little difference to the results.

In the main, our findings in Table 1 provide little evidence that the Wisconsin Supreme Court decision impacted social distancing. With regard to stay-at-home behavior as measured on the extensive margin (Panel I), three of the four estimated treatment effects are positive and one is negative; all are economically small and statistically indistinguishable from zero. While the effects of the repeal on stay-at-home behaviors at the intensive margin are negative (Panel II), the magnitudes are not economically or statistically significant (representing about a 3-4 percent decline relative to the baseline mean).

We do find some suggestive evidence of increased activity at restaurants and bars (Panel III), on the order of about a 12 to 16 percent increase in foot-traffic at these venues, though only the estimate in column (4) is significant at the weakest conventional level $(p<0.1)$. These reflect an average effect over the entire post-repeal period, and as indicated in Figures 1 and 2, the increases in foot-traffic and decreases in time spent at home are not persistent, with little discernible difference in social distancing between Wisconsin and the control group by the end

distance from Wisconsin's repeal. Making this latter restriction even more stringent, by including states with a SIPO expiration only if they have 3 or fewer days of post-treatment data (meaning their SIPO expired on May 31 or later) limits our primary donor pool to 14 states, but yields estimates that are highly similar. 
of the analysis period. We do not uncover any meaningful increases in mobility at retail establishments. $^{27}$

\subsection{Wisconsin’s SIPO Repeal and COVID-19 Confirmed Cases}

Figure 3 presents effects of the repeal on confirmed cases, by graphing trends between Wisconsin and its synthetic counterfactual. Trends in confirmed cases identically track across Wisconsin and synthetic Wisconsin over the entire sample period, providing no sign that the repeal of the statewide SIPO led to any discernible increase in confirmed infections. These patterns are robust to functional form, that is modeling the trends in terms of the case rate versus the natural log of the case rate, and robust to the matching algorithms. Estimates in Table 2 confirm these findings. ${ }^{28}$

One concern regarding the lack of any strong effects for COVID-19 cases is that the postrepeal sample period might not be sufficiently long enough to detect a resurgence or increase in infection rates. While this is a possibility, we note that our sample includes three weeks of data following the revocation of the statewide SIPO. The median incubation period for COVID-19 is 5.1 days, with $75 \%$ of all infected individuals seeing symptoms within 6.7 days and $97.5 \%$ in

\footnotetext{
${ }^{27}$ Effects on foot-traffic in other venues were statistically insignificant in all models, with point estimates suggesting an average increase of 4.8 to 12.3 percent increase in entertainment venues, 4.2 to 8.7 percent increase in business services, and an overall 5.1 to 7.3 percent increase in foot-traffic across all of these venues plus restaurants, bars, and retail establishments.

${ }^{28}$ Appendix Table 2 reports the donor states receiving positive weights for each analysis in Table 2. In Appendix Table 3, we present alternate estimates of Wisconsin's repeal on COVID-19 cases over a 14-day post-repeal period. In doing so, we are able to impose a very strict standard on our donor pool, comprising states that had a SIPO in place over the entire analysis period (from May 3 through May 26) and states whose SIPOs expired with 5 or fewer days of post-treatment data. Given that the median incubation period of the virus for symptom presentation is 5.1 days, the latter restriction ensures that the control group will not be contaminated from these other SIPO expirations, which would otherwise have attenuated the estimated treatment effects. These results continue to suggest that there were no significant or meaningful increases in COVID-19 cases due to Wisconsin rescinding its SIPO, in this case up to two weeks following the repeal.
} 
11.5 days (Lauer et al. 2020). Prior work has uncovered strong effects of shelter-in-place orders on confirmed cases well within our post-treatment period (Friedson et al. 2020; Dave et al. 2020a, b; Courtemanche et al. 2020a, b). Hence, if there are any meaningful changes in COVID19 cases as a result of the repeal, our post-repeal window of 21 days would capture them. In Figure 4, we further extend the post-repeal window to June 12, spanning a full month following the lifting of Wisconsin's SIPO. ${ }^{29}$ There is little here to indicate that repealing the SIPO significantly or substantially increased COVID-19 cases even up to a month following the repeal.

Could our findings that the repeal of the Wisconsin SIPO had no effect on COVID-19 cases simply suggest that the implementation of Wisconsin's SIPO was ineffective at curbing COVID-19 cases? This is unlikely. Estimates in the literature consistently show that SIPOs are effective in curbing case growth (Friedson et al. 2020; Dave et al. 2020a, b; Courtemanche et al. 2020a, b), particularly among early adopters, which includes Wisconsin. Additionally, when we compare Wisconsin to synthetic Wisconsin over the period that enveloped the initial SIPO adoption (March 15 through May 9) but predated the repeal, we find strong evidence that adoption of the statewide SIPO was effective in increasing social distancing and flattening the growth in COVID-19 cases (Appendix Figure 3). In this context, Wisconsin is not an outlier and experienced the same substantial dampening in the growth in COVID-19 cases, which has been uncovered in the literature with respect to the effectiveness of a statewide shelter-in-place mandate adopted relatively early in the outbreak cycle (Dave et al. 2020a). Our results thus far,

\footnotetext{
${ }^{29}$ As noted above, the donor pool for our month-long analysis is comprised of 14 states. Our primary donor pool consists, as before, of states with a SIPO in effect throughout the analysis period (from May 3 through June 12) and states whose SIPOs expired closer to the end of the sample period (that is states with less than 12 days from the state's lifting of its SIPO). This latter restriction means that a state whose SIPO expired would be part of the donor pool only if their order expired on or after June $1^{\text {st }}$, widening the temporal distance between Wisconsin's SIPO repeal and another state's SIPO expiration, to at least 19 days or more, if that state is part of the synthetic control. This again minimizes any contamination of our control group from effects of other states lifting their SIPOs.
} 
however, indicate that rescinding this mandate has not been symmetric in terms of undoing these public health benefits up to a month following the revocation.

\subsection{Heterogeneity in the Effects of the Supreme Court Repeal}

We next assess whether the average (null) policy response is masking heterogeneity across important margins that vary spatially. We present these results in Table 3, based on the difference-in-differences setup (equations 1 and 2) applied to county-by-day data.

Panel I presents the baseline estimates, based on equation (1). They suggest some negative effects on stay-at-home behaviors at the intensive margin, though the effects are small and not statistically significant at conventional levels. ${ }^{30}$

In Panel II, we assess whether Wisconsinites residing in the 58 counties that accepted the Supreme Court's cancellation of the SIPO (which we refer to as "Bound Wisconsin"), responded any differently from those residing in the other 14 counties, which had countered the ruling by extending their local orders. ${ }^{31}$ We uncover some evidence that foot-traffic at restaurants and bars increased more for bound counties relative to the counties that extended their local orders. Specifically, foot-traffic at these venues increased by a marginally significant 18.9 percent in the non-extending counties, compared with an insignificant 3.6 percent decline among residents in counties that extended the local SIPO. ${ }^{32}$ These patterns however do not carry over to the other measures of social distancing.

\footnotetext{
${ }^{30}$ Estimates from models that alternately control for state-linear trends are presented in Appendix Table 4. The results are largely unaffected.

${ }^{31}$ Appendix Figure 4 shows the growth in cases across these sets of counties, prior to the repeal, and do not show any systematic difference between counties that extended their local orders and those that undertook no response.

${ }^{32}$ When we consider differential responses across the five counties that extended their local order longer versus the remaining 67 counties that lost SIPO coverage right away or within a few days of the Supreme Court ruling (Appendix Table 5, Panel I), we find no meaningful differences in any of the social distancing measures or in COVID-19 cases.
} 
Importantly, we find no evidence that SIPO repeal increased COVID-19 cases in counties that did not extend their local orders. Rather, we find that in these counties, SIPO repeal is associated with a statistically insignificant and small in magnitude decline in COVID-19 cases.

As an alternative approach for addressing the fact that certain Wisconsin counties were more fully bound by the Supreme Court decision that others, we once again create a "Bound Wisconsin” jurisdiction comprised of the 58 counties for which the court order applied at the ruling. Then we use the donor pool of SIPO states to match our bound treatment jurisdiction. While we find that "Bound Wisconsin" experienced a 20 to 23 percent increase in foot traffic in restaurants and bars (see Appendix Table 6), we continue to find no substantial increases or acceleration in the trend of COVID-19 cases following the repeal (see Figure 5 panels a and $b$ and Appendix Table 7). ${ }^{33}$ Furthermore, when narrowing the lens to specifically those parts of bound Wisconsin which experience a relatively larger (above median) increase in foot-traffic at restaurants and bars following the Supreme Court decision, there is again no indication of any statistically or economically significant rise in COVID-19 cases or break in the trend growth following the repeal (Figure 6).

Other studies have detected secondary spread of COVID-19 in data on infections within three weeks of likely initial contact (Mangrum and Niekamp 2020; Dave et al. 2020a,b; Friedson et al. 2020; Courtemanche et al. 2020), meaning that our three-week post-ruling window is likely sufficient to capture the first wave of potential infections resulting from the repeal of

\footnotetext{
${ }^{33}$ We replicate our main analyses using only within-Wisconsin variation, driven by the county-level counterextenders to the lifting of the state order. While this variation appears to be orthogonal to pre-repeal growth rates across extending and non-extending counties (see Appendix Figure 4), we interpret these results with some caution. These analyses, nevertheless, also confirm that our across-the-board nil effects are not masking important intra-state effects. While we find evidence that SIPO expiration increased mobility outside the home $(0.2$ hour decline in median hours spent at home, and a significant 4-15 percent increase in foot-traffic at bars/restaurants and retail venues), from the lifting of a county-level SIPO, the decrease in stay-at-home behaviors is fairly small and does not translate into any significant increase in confirmed COVID-19 infections.
} 
Wisconsin's SIPO. However, if we extend the synthetic control post-treatment analysis to up to a month (June 12) with a modestly reduced donor pool, ${ }^{34}$ we still find no significant or substantial impact on COVID-19 cases in counties bound by the Supreme Court ruling (Figure 5 panels c and d).

As we do not find any significant effects on COVID-19 cases, it is not plausible to expect any effects on mortality. Nevertheless, assessing effects on deaths serves as an additional validation check, since death counts represent an objective measure of COVID-19 infections that is less plagued with measurement error in confirmed case counts and selection into testing. As with cases, Figure 7 indicates no significant or systematic increase in deaths over a post-repeal period of one month in bound Wisconsin relative to its counterfactual.

Next, we assess whether the null effects we find in relation to the repeal in Wisconsin are conflating differential effects across urban and non-urban areas. Panel III of Table 3 presents these results, comparing policy responses across urbanized vs. non-urbanized counties in Wisconsin. ${ }^{35}$ These estimates indicate a somewhat larger increase in mobility patterns centered around bars and restaurants in less urbanized areas, though the effects are imprecisely estimated and the results for stay-at-home behaviors are not consistent with this pattern.

The U.S. response to the COVID-19 outbreak, to some extent, has been divided along partisan lines (Simonov et al. 2020). In Panel IV of Table 3, we assess if responses in stay-athome behaviors vary based on ideology, as measured by the share of Trump voters in the county. Here we find some weak evidence that counties, wherein the majority of voters voted for Trump, experienced somewhat larger declines in stay-at-home behaviors (time spent at home) and a

\footnotetext{
${ }^{34}$ As noted above, extending the post-treatment window to one month requires a four state reduction in the donor pool to ensure that no state in the pool includes post-SIPO repeal data following the COVID-19 incubation period. 35 Appendix Table 5 (Panel II) shows similar results when we assess effects across population density.
} 
larger increase in foot-traffic at bars and restaurants relative to counties in which the share of Trump voters was below 50\%. This is consistent with research indicating that individuals residing in counties with a higher share of Trump voters are less likely to engage effort in searching for information on the coronavirus and follow social distancing guidelines (Barrios and Hochberg 2020).

Despite some evidence of heterogeneous effects on social distancing by urbanicity, population density, and ideology, results (column 5) provide no consistent or meaningful differences in the effects on COVID-19 cases across these margins.

\section{Conclusion}

Isolating the causal effect of SIPO repeal on COVID-19-related health outcomes is difficult due to policymakers' explicit linking of COVID-19 case growth to SIPO lifting. The sudden and largely unanticipated removal of Wisconsin's SIPO through the Wisconsin Legislature v. Palm Wisconsin Supreme Court ruling created a unique opportunity to examine a statewide SIPO that was not explicitly contingent on pre-existing trends in COVID-19 case growth.

We find that the removal of the SIPO had only modest effects on measures of social distancing behavior, causing individuals to venture outside of their homes more often and increase their visits to bars and restaurants. Other measures of distancing were largely unaffected. The increases in mobility were somewhat larger in less densely populated and less urbanized areas, and locations that disproportionately supported President Trump in the 2016 presidential election. These findings are not due to some counties enacting their own SIPOs after the statewide order was struck down. 
This indicates that the effect of lifting a SIPO is not necessarily symmetric to that of first enacting the order. For example, mobility outside of one's home is a function of many factors, including risk perceptions and knowledge of risk-mitigation behavior, which can change over time. SIPOs may have been enacted during a time when people perceived little risk and knew little about proper protective behavior, and thus were binding in a powerful way to curb sociallydriven infection. Then, SIPOs might have been lifted after perceptions and behavior had a chance to adjust, meaning that individuals might have engaged in social distancing behavior even without the presence of the policy. Thus, in the case of Wisconsin, it is possible that the SIPO may have been less binding at the time it was struck down. Of course, other factors could also be at play, such as outside options for economic and non-economic activity worsening due to the outbreak.

The asymmetry in the effects of enacting a SIPO versus its revocation also illuminates an important pathway that may underlie why SIPOs have been found to be effective. Prior studies (Dave et al. 2020a,b; Cronin and Evans 2020; Sears et al. 2020; Gupta et al. 2020) have recognized that the effects of a SIPO potentially reflect both direct restrictions on individuals' interactions as well as a bundled information shock that may lead individuals to self-regulate and constrain their mobility. In other words, SIPOs may induce greater social distancing both by increasing the costs associated with interactions (or mobility) and also by shifting individuals' risk perceptions. However, beyond acknowledging the presence of these reinforcing pathways, it has not been possible to more definitively comment on the relative importance of each.

Our study of the Wisconsin Supreme Court sheds some light on this question. The unanticipated repeal of Wisconsin's statewide SIPO on constitutionality grounds shifted the legal environment and eliminated the direct restrictions on individuals' mobility. However, given the 
nature of the judicial decision, and the fact that it was largely delinked from public health considerations, the repeal would not be expected to substantially shift individuals' perceived risk or information set. Our finding that this repeal did not have any substantial or persistent effects on social distancing suggests that the information channel underlying SIPO adoption may be more salient for motivating population-based mitigating behaviors against COVID-19 spread.

Our key finding that the decision in Wisconsin Legislature v. Palm had little effect on COVID-19 case growth may be explained not only by the lack of large changes in social distancing, but also by individuals successfully engaging in avoidance behaviors on other margins (such as mask-wearing). Lifting SIPOs only implies that individuals regain the right to engage in certain public behaviors. It does not mean that individuals will exercise that right, and that if they do, they will not do so responsibly.

The results described above come with some caveats. First, with regard to external validity, it is possible that if the average state experienced a similar supreme court decision then it may have had a very different experience. However, along many important economic and political dimensions that may be related to COVID-19 policy response, Wisconsin is very close to an "average” U.S. state. Politically, Wisconsin is a "swing” state (Hagen 2020). Also, according to the 2018 American Community Survey, Wisconsin ranks $25^{\text {th }}$ out of 51 in median household income and $24^{\text {th }}$ out of 51 for percent of the population with at least a bachelor's degree. ${ }^{36,37}$

\footnotetext{
${ }^{36}$ Income statistics can be found at: https://www.census.gov/data/tables/time-series/demo/income-poverty/historicalincome-households.html, and education statistics can be found at https://ncses.nsf.gov/indicators/states/indicator/bachelors-degree-holders-per-25-44-year-olds/table.

${ }^{37}$ Of course, we acknowledge that Wisconsin does differ on other relevant dimensions, including urbanicity rate, according to the U.S. Census (ranking $34^{\text {th }}$ out of 51 ) and in the share of non-Hispanic white residents (ranking $13^{\text {th }}$ of 51), according to the American Community Survey.
} 
Secondly, while the court decision in Wisconsin Legislature v. Palm was unique, its uniqueness along a key dimension — delinking the decision to terminate a SIPO from immediate prior COVID-19-related health — offers important advantages in our understanding of policy. Given the close relationship between opening policies and trends in cases, having a natural experiment that is as sudden and clean as the Wisconsin Legislature v. Palm decision is important for causal identification. But perhaps even more importantly, this experiment allows a unique opportunity to infer the role of information as a mechanism. There are few situations where the information component of a change in NPI policy is largely separated from the legal obligations of the NPI. Thus, the Wisconsin Legislature v. Palm decision provides an important window on how the legal changes operate independently from health-related information shocks. We believe that these advantages make the above study incredibly valuable for policymakers, including a fuller understanding of the potential asymmetric effects from SIPO lifting and adoption. 


\section{References}

Abadie, A., Diamond, A. and Hainmueller, J. (2010). "Synthetic Control Methods for Comparative Case Studies: Estimating the Effect of California's Tobacco Control Program.” Journal of the American Statistical Association 105 (490): 493-505.

Abouk, R, and Heydari, B. (2020). "The Immediate Effect of COVID-19 Policies on Social Distancing Behavior in the United States.” Retrieved from SSRN: https://ssrn.com/abstract=3571421

Andersen, M., Maclean, J.C., Pesko, M.F., and Simon, K.I. (2020). “Effect of a Federal Paid Sick Leave Mandate on Working and Staying at Home: Evidence from Cellular Device Data.” NBER Working Paper No. 27138.

Baek, C., McCrory, P.B., Messer, T., and Mui, P. (2020). "Unemployment Effects of Stay-atHome Orders: Evidence from High Frequency Claims Data” IRLE Working Paper \#10120.

Barrios, J.M. and Hochberg, Y. (2020). "Risk Perception Through the Lens of Politics in the Time of the COVID-19 Pandemic.” NBER Working Paper No. 27008.

Beck, M. (2020, May 13). "Wisconsin Supreme Court strikes down Governor’s stay-at-home order.” USA Today.

Botosaru, I., \& Ferman, B. (2019). “On the Role of Covariates in the Synthetic Control Method." The Econometrics Journal 22(2): 117-130.

Cameron, A.C. and D. Miller. (2015). “A Practitioner’s Guide to Cluster-Robust Inference.” Journal of Human Resources, 50(2): 317-372

Centers for Disease Control and Prevention. (2020). "CDC Activities and Initiatives Supporting the COVID-19 Response and the President's Plan for Opening America Up Again.” Retrieved from: https://www.cdc.gov/coronavirus/2019-ncov/downloads/php/CDCActivities-Initiatives-for-COVID-19-Response.pdf

Colliver, V. (2020, May26). "Santa Clara Health Officer Suggests California is Reopening Too Soon.” Politico.

Cotti, C.D., Engelhardt, B., Foster, J., Nesson, E.J., and Niekamp, P.S. (2020). “The Relationship between In-Person Voting, Consolidated Polling Locations, and Absentee Voting on Covid-19: Evidence from the Wisconsin Primary.” NBER Working Paper No. 27187.

Couch, K.A., Fairlie, R.W. and Xu, H. (2020). "The Impacts of COVID-19 on Minority Unemployment: First Evidence from 2020 CPS Microdata.” IZA Discussion Paper No. 13264.

Courtemanche, C., Garuccio, J., Le, A., Pinkston, J. and Yelowitz, A., (2020a). "Strong Social Distancing Measures In The United States Reduced The COVID-19 Growth Rate: Study Evaluates The Impact Of Social Distancing Measures on The Growth Rate of Confirmed COVID-19 Cases Across the United States.” Health Affairs, pp.10-1377.

Courtemanche, C.J., Garuccio, J., Le, A., Pinkston, J.C. and Yelowitz, A., (2020b). "Did SocialDistancing Measures in Kentucky Help to Flatten the COVID-19 Curve?” Working Paper.

Cronin, C. J., \& Evans, W. N. (2020). "Private Precaution and Public Restrictions: What Drives Social Distancing and Industry Foot Traffic in the COVID-19 Era?” NBER Working Paper No. 27531. 
Cunningham, S. and Shah, M., (2018). “Decriminalizing Indoor Prostitution: Implications for Sexual Violence and Public Health.” The Review of Economic Studies, 85(3), pp.16831715.

Dave, D.M., Friedson, A.I., Matsuzawa, K. and Sabia, J.J., (2020a). "When Do Shelter-In-Place Orders Fight COVID-19 Best? Policy Heterogeneity Across States and Adoption Time.” Economic Inquiry, forthcoming.

Dave, D.M., Friedson, A.I., Matsuzawa, K. Sabia, J.J., and Safford, S. (2020b). "Were Urban Cowboys Enough to Control COVID-19? Local Shelter-In-Place Orders and Coronavirus Case Growth.” Journal of Urban Economics, forthcoming.

Dave, Dhaval M., Andrew I. Friedson, Drew McNichols, and Joseph J. Sabia. (2020c). “The contagion externality of a superspreading event: The Sturgis Motorcycle Rally and COVID-19.” NBER Working Paper No. 27813.

Dave, D. M., Friedson, A. I., Matsuzawa, K., McNichols, D., Redpath, C., \& Sabia, J. J. (2020d). "Risk Aversion, Offsetting Community Effects, and COVID-19: Evidence from and Indoor Political Rally.” NBER Working Paper No. 27522.

Deliso, M. (2020, May 14). "Governor Reacts to State Supreme Court Blocking Stay-At-Home Order.” ABC News.

Doyle, O., (2020). “COVID-19: Exacerbating Educational Inequalities?” Working Paper.

Fadel, L., (2020, May 9). Public Health Experts Say Many States Are Opening Too Soon To Do So Safely. National Public Radio.

Ferman, B., Pinto, C. and Possebom, V. (2020), Cherry Picking with Synthetic Controls. Journal of Policy Analysis and Management 39: 510-532.

Friedson, A.I., McNichols, D., Sabia, J.J. and Dave, D., (2020). "Shelter in Place Orders and Public Health: Evidence from California During the COVID-19 Pandemic.” Journal of Policy Analysis and Management, forthcoming.

Galea, S., Merchant, R.M. and Lurie, N. (2020). "The Mental Health Consequences of COVID19 And Physical Distancing: The Need for Prevention and Early Intervention.” JAMA Internal Medicine.

Goodman-Bacon, A., and Marcus, J. (2020). "Using Difference-in-Differences to Identify Causal Effects of COVID-19 Policies.” Working Paper.

Gupta, S., Nguyen, T. D., Rojas, F. L., Raman, S., Lee, B., Bento, A., Simon, K. and Wing, C. (2020). Tracking public and private response to the covid-19 epidemic: Evidence from state and local government actions.” NBER Working Paper No. w27027.

Hagemann, H. (2020, May 13). "Wisconsin Supreme Court Overturns the State's Stay-At-Home Orders." NPR.

Hagen, Lisa. (2020, September 2). "The Battleground States: Wisconsin" U.S. News and World Report. Available: https://www.usnews.com/news/elections/articles/the-2020-swingstates-wisconsin-who-votes-past-results-and-why-it-matters

Hansen, B., Miller, K. and Weber, C., (2020). "Early Evidence on Recreational Marijuana Legalization and Traffic Fatalities.” Economic inquiry, 58(2), pp.547-568.

Hsing, A., Zhang, J.S., Peng, K., Lin, W.K., Wu, Y.H., Hsing, J.C., LaDuke, P., Heaney, C., Lu, Y. and Lounsbury, D.W. (2020). "A Rapid Assessment of Psychological Distress and Well-Being: Impact of the COVID-19 Pandemic and Shelter-in-Place.” Retrieved from: SSRN 3578809. 
Holtz, D., Zhao, M., Benzell, S.G., Cao, C.Y., Rahimian, M.A., Yang, J., Allen, J., Collis, A., Moehring, A., Sowrirajan, T., Ghosh, D., Zhang, Y., Dhillon, P., Nicolaides, C., Eckles, D., and Aral, S. (2020). "Interdependence and the Cost of Uncoordinated Responses to COVID-19” Working Paper.

Jarvie, J. (2020, May 23), "Georgia Reopened First, What The Data Show Is a Matter of Fierce Debate.” Los Angeles Times.

Jimenez, O. and LeBlanc, P. (2020, May 14). “Wisconsin Supreme Court Strikes Down State’s Stay-At-Home Orders” CNN.

Johnson, S. (2020, May 5). “As State Supreme Court Hears Arguments, Wisconsin’s Stay-AtHome Order Hangs in Balance.” Wisconsin Public Radio.

Kaul, A., Klößner, S., Gregor, P. and Schieler, M. (2015). "Synthetic Control Methods: Never Use All Pre-Intervention Outcomes Together with Covariates.” Working Paper, Saarland University, Saarbrucken, Saarland, Germany

Lasry, A., Kidder, D., Hast, M., Poovey, J., Sunshine, G., Zviedrite, N., Ahmed, F. and Ethier, K.A., (2020). "Timing of Community Mitigation And Changes in Reported COVID-19 And Community Mobility-Four US metropolitan Areas." Morbidity and Mortality Weekly Report, 69(15): 451-457.

Lauer, Stephen A., Kyra H. Grantz, Qifang Bi, Forrest K. Jones, Qulu Zheng, Hannah R. Meredith, Andrew S. Azman, Nicholas G. Reich, and Justin Lessler. "The Incubation Period of Coronavirus Disease 2019 (COVID-19) from Publicly Reported Confirmed Cases: Estimation and Application.” Annals of Internal Medicine (2020).

Lazzerini, M., Barbi, E., Apicella, A., Marchetti, F., Cardinale, F. and Trobia, G. (2020). "Delayed Access or Provision of Care in Italy Resulting From Fear of COVID-19." The Lancet Child \& Adolescent Health, 4(5), pp.e10-e11.

Mangrum, D. and Niekamp, P. (2020). "College Student Contribution to Local COVID-19 Spread: Evidence from University Spring Break Timing.” Retrieved from SSRN: https://papers.ssrn.com/sol3/Papers.cfm?abstract_id=3606811

Millhiser, I. (2020, May 5). “A Republican Lawsuit Could Force Wisconsin to Reopen Immediately.” Vox.

Newsday Staff. (2020, May 22). “Cuomo: Long Island and Mid-Hudson Regions On Track to Begin Reopening Soon” Newsday. Retrieved from: https://www.newsday.com/news/health/coronavirus/coronavirus-long-island-new-york1.44850649

New York Forward. (2020). “Metrics to Guide Reopening New York” Retrieved from: https://forward.ny.gov/metrics-guide-reopening-new-york

O’Kane, C. (2020, May 15). Wisconsin bars packed with patrons almost immediately after court strikes down stay-at-home order. CBS News.

Office of the Governor. (2020). “Emergency Order \#28 Safer at Home Order.” Retrieved from: https://evers.wi.gov/Documents/COVID19/EMO28-SaferAtHome.pdf

Oregon Health Authority. (2020). "Building a Safe and Strong Oregon | Reopening Criteria” Retrieved from: https://govstatus.egov.com/OR-OHA-Reopening-Framework

Richmond, T. (2020, May 18). "Evers Gives Up On Virus Restrictions Amidst GOP Opposition.” AP Wire Service.

Ruthhart, B. (2020, May 14). "Wisconsin Now Without COVID-19 Restrictions After State Supreme Court Strikes Down Gov. Tony Evers’ Stay-At-Home Order.” Chicago Tribune. 
Santioli, J.M., Lindley, M.C., DeSilva, M.B., Kharbanda, E.O., Daley, M.F., Galloway, L., Gee, J, Glover, M., Herring, B., Kang, Y., Lucas, P., Noblit, C., Tropper, J., Vogt, T., and Weintraub, E. (2020) "Effects of the COVID-19 Pandemic on Routine Pediatric Vaccine Ordering and Administration.” Morbidity and Mortality Weekly Report, 69(19):591-593.

Sears, James and Villas-Boas, J. Miguel and Villas-Boas, Vasco and Villas-Boas, Sofia, Are We \#StayingHome to Flatten the Curve? (2020). Department of Agricultural and Resource Economics. CUDARE Working Papers. . Available at SSRN: https://ssrn.com/abstract=3569791.

Simonov, A., Sacher, S., Dubé, J.P. and Biswas, S. (2020). “The Persuasive Effect of Fox News: Non-Compliance with Social Distancing During the Covid-19 Pandemic.” NBER Working Paper No. 27237.

State of Wisconsin. (2020). “Gov. Evers Directs DHS to Issue Safer at Home Order.” Retrieved from: https://content.govdelivery.com/accounts/WIGOV/bulletins/282deef

Supreme Court of Wisconsin (2020). "Wisconsin Legislature v. Secretary-Designee Andrea Palm, Julie Willems Van Dijk and Lisa Olson, In Their Official Capacities As Executives of Wisconsin Department of Health Services.” Retrieved from "https://wicourts.gov/sc/opinion/DisplayDocument.pdf?content=pdf\&seqNo=260868

Usero, A. (2020, May 27) "Reopening Too soon: Lessons From the Deadly Second Wave of the 1918 Flu Pandemic.” Washington Post.

Vainshtein, A. (2020, May 1). "Save the Economy or Save Lives: Bay Area Residents Debate Morality of Shelter In Place.” San Francisco Chronicle.

Vetterkind, R. (2020, May 14). "Wisconsin Supreme Court Strikes Down Stay-At-Home Order; Dane County Institutes Local Order.” Wisconsin State Journal.

Wisconsin Department of Health Services. (2020). “COVID-19: Wisconsin Summary Data” Retrieved from: https://www.dhs.wisconsin.gov/covid-19/data.htm

Wisconsin Legislature v. Palm, 2020AP765-OA (Wisconsin Supreme Court 2020).

WisContext. (2020). "What The COVID-19 Pandemic Looks Like In Wisconsin: Maps And Charts.” Retrieved from: https://www.wiscontext.org/what-covid-19-pandemic-lookswisconsin-maps-and-charts

White House. (2020). “Guidelines for Opening up America Again” Retrieved from: https://www.whitehouse.gov/openingamerica/ 
Figure 1. Synthetic Control Estimates of Effects of Wisconsin Supreme Court Abolition of SIPO on Stay-at-Home Behavior

Panel (a): Percent at Home Full-Time, Match on All Pre-Treat Days

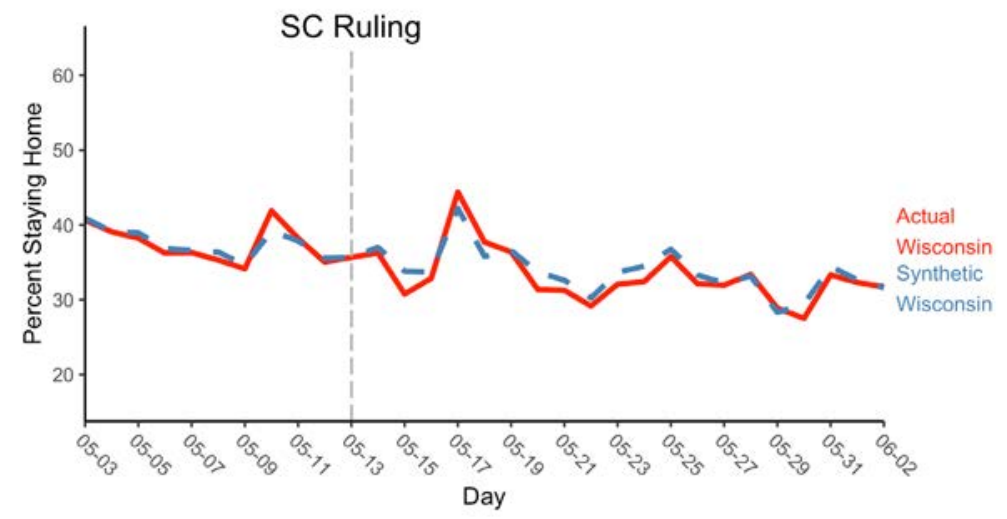

Note: Synthetic WI is comprised of IL (.527), LA (.249), NM (.195), \& MI (.028).

Panel (c): Median Hours at Home, Match on All Pre-Treat Days

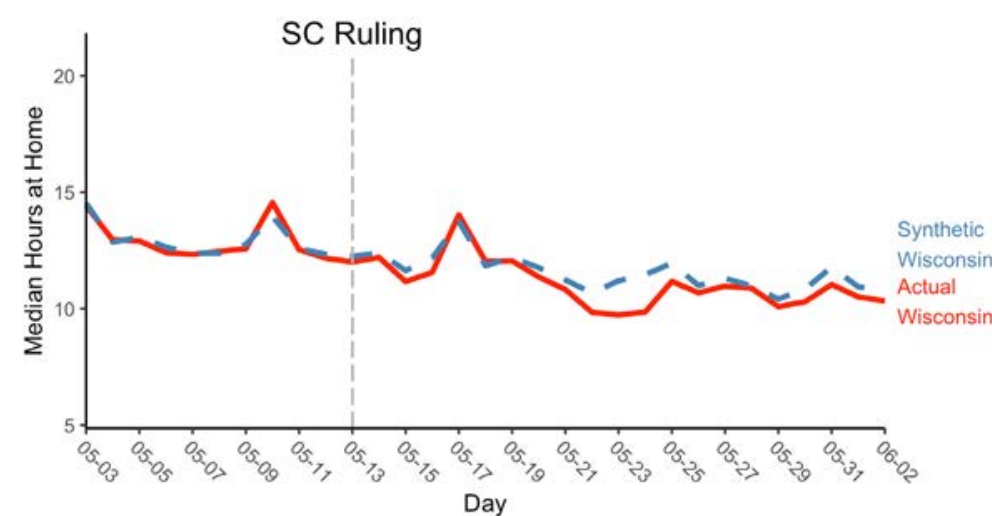

Note: Svnthetic WI is comprised of NM (.466), IL (.412), \& OH (.122).
Panel (b): Percent at Home Full-Time, Match on 5 Pre-Treat Days and All Observables

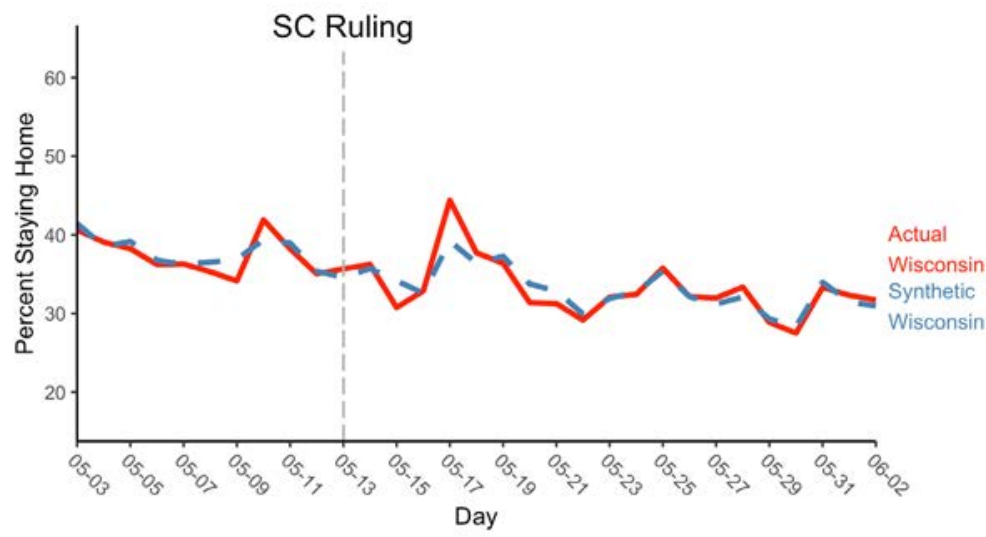

Note: Synthetic WI is comprised of OH (.532), ME (.237), \& IL (.231)

Panel (d): Median Hours at Home, Match on 5 Pre-Treat Days and All Observables

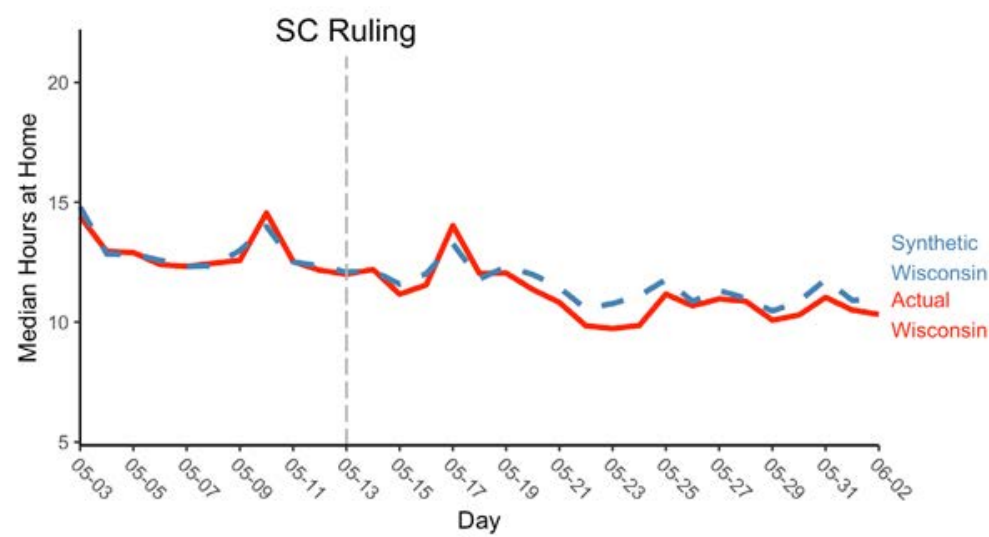

Note: Synthetic WI is comprised of NC (.545), IL (.239), \& ME (.208). 
Figure 2. Synthetic Control Estimates of Effect of Wisconsin Supreme Court Abolition of SIPO on Log (Foot Traffic Per 100,000 Pop)

Panel (a): Restaurants or Bars, Match on All Pre-Treat Days

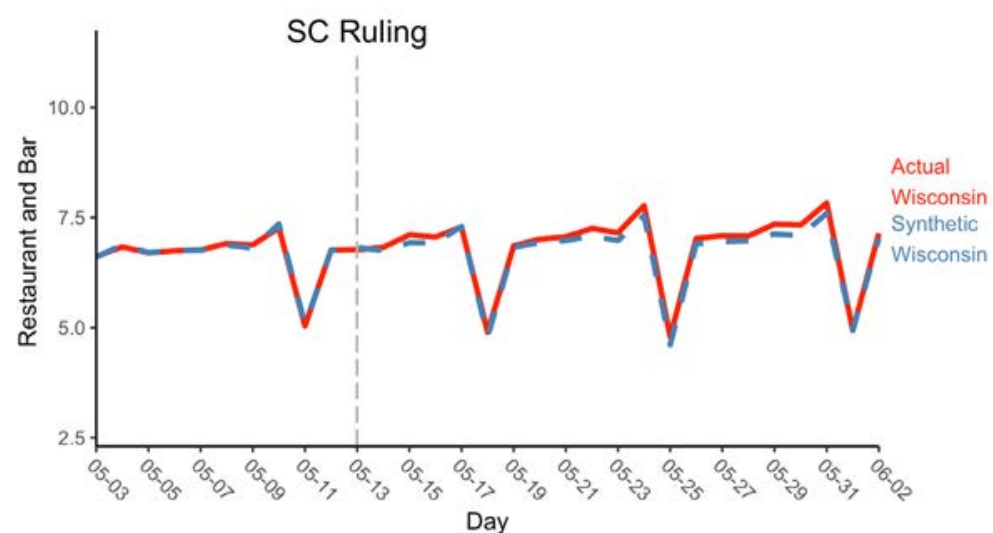

Note: Synthetic WI is comprised of MI (.684), NH (.218), \& NM (.098).

Panel (c): Retail, Match on All Pre-Treat Days

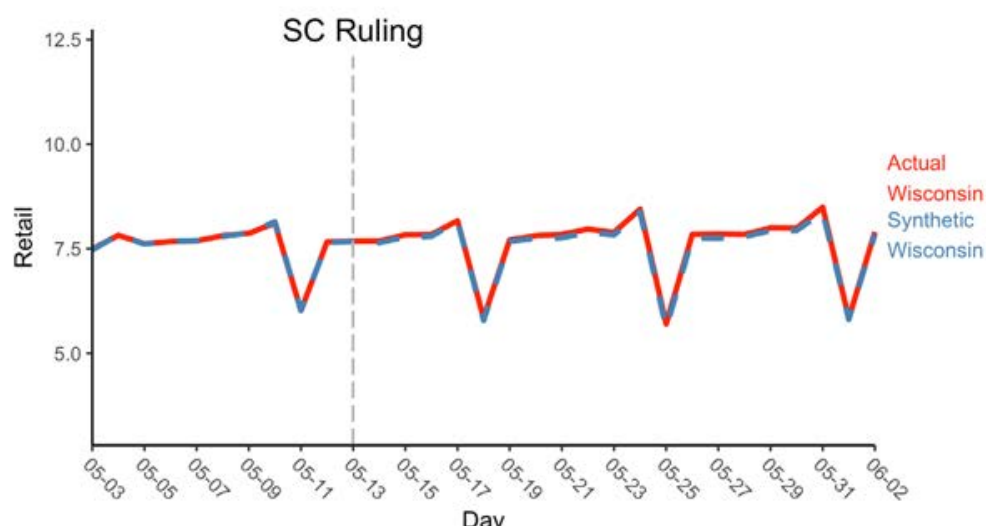

Note: Synthetic WI is comprised of IL (.862), NH (.095), \& MI (.013).
Panel (b): Restaurants or Bars, Match on 5 Pre-Treat Days and All Observables

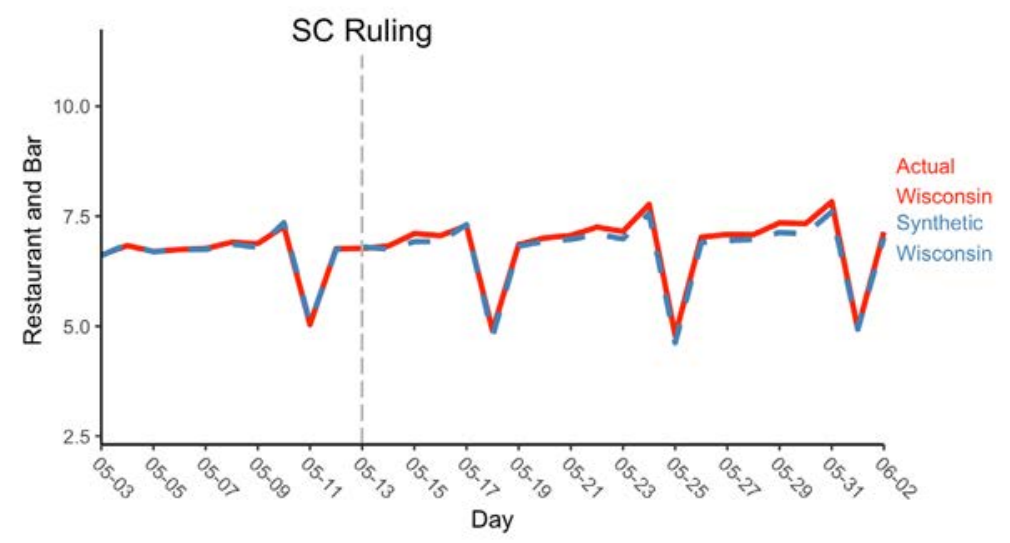

Note: Synthetic WI is comprised of MI (.626), NH (.298), NM (.052), LA (.011), \& ME (.010).

Panel (d): Retail, Match on 5 Pre-Treat Days and All Observables

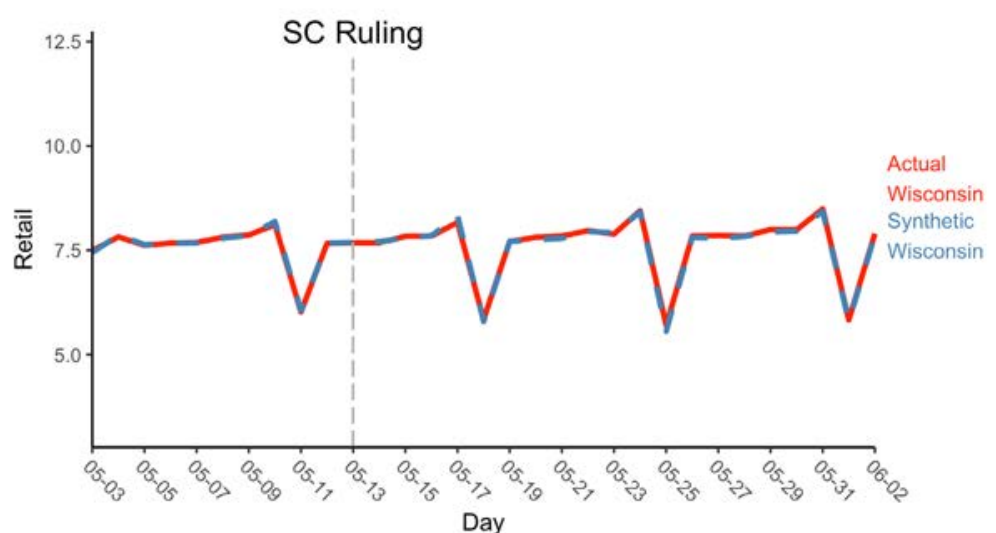

Note: Synthetic WI is comprised of OH (.290), NC (.239), NH (.212), CA (.132), ME (.099), \& VA (.011) 
Figure 3. Synthetic Control Estimates of Effect of Wisconsin Supreme Court Abolition of SIPO on COVID-19 Cases Per 100,000 Population

Panel (a): COVID-19 Case Rate Levels, Match on All Pre-Treat Days

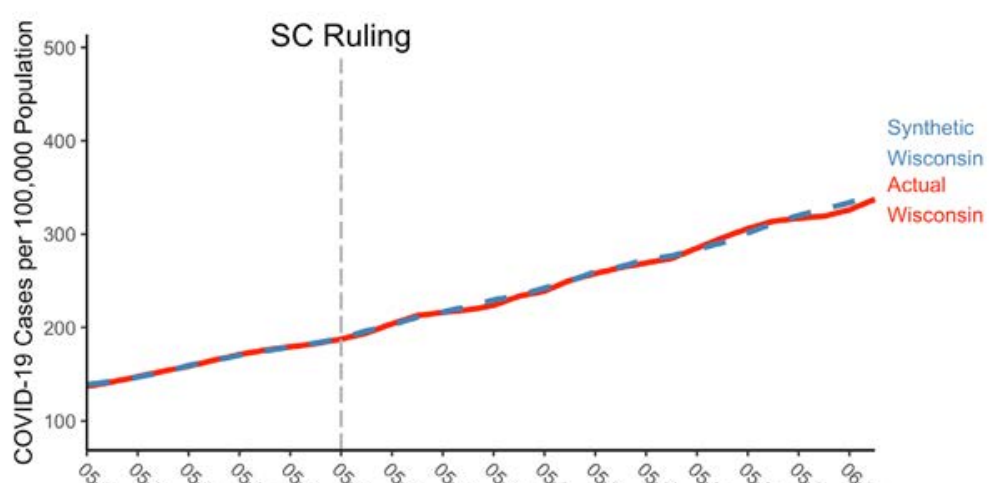

Panel (c): Log (COVID-19 Case Rate), Match on All Pre-Treat Days

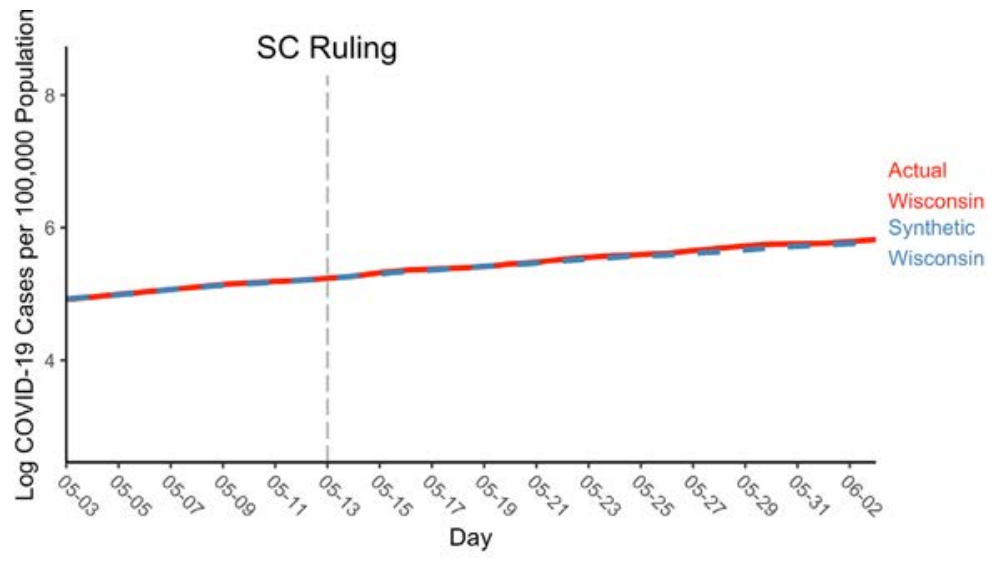

Note: Synthetic WI is comprised of NC (.711), NM (.059), VA (.055), CA (.032), \& IL (.02).
Panel (b): COVID-19 Case Rate Levels, Match on 5 Pre-Treat Days and All Observables

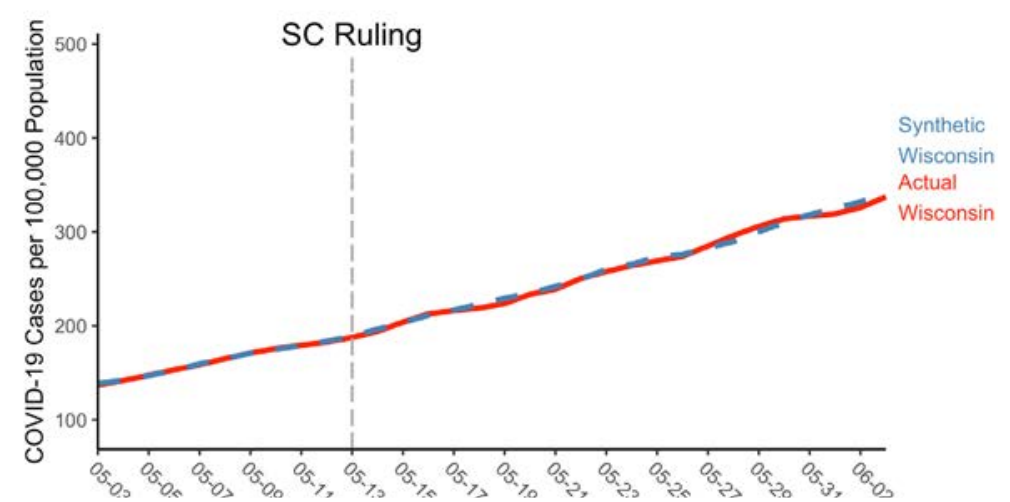

Panel (d): Log (COVID-19 Case Rate), Match on 5 Pre-Treat Days

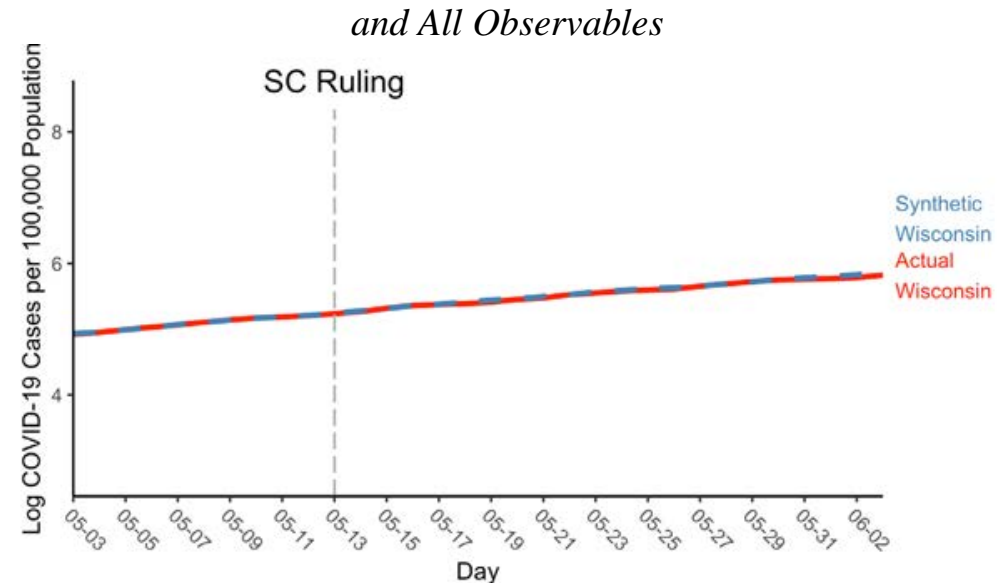

Note: Synthetic WI is comprised of NC (.753), VA (.113), \& CA (.027). 
Figure 4. Robustness of COVID-19 Case Effect of Wisconsin Supreme Court Decision to Use of a Full Month of Post-Treatment Data

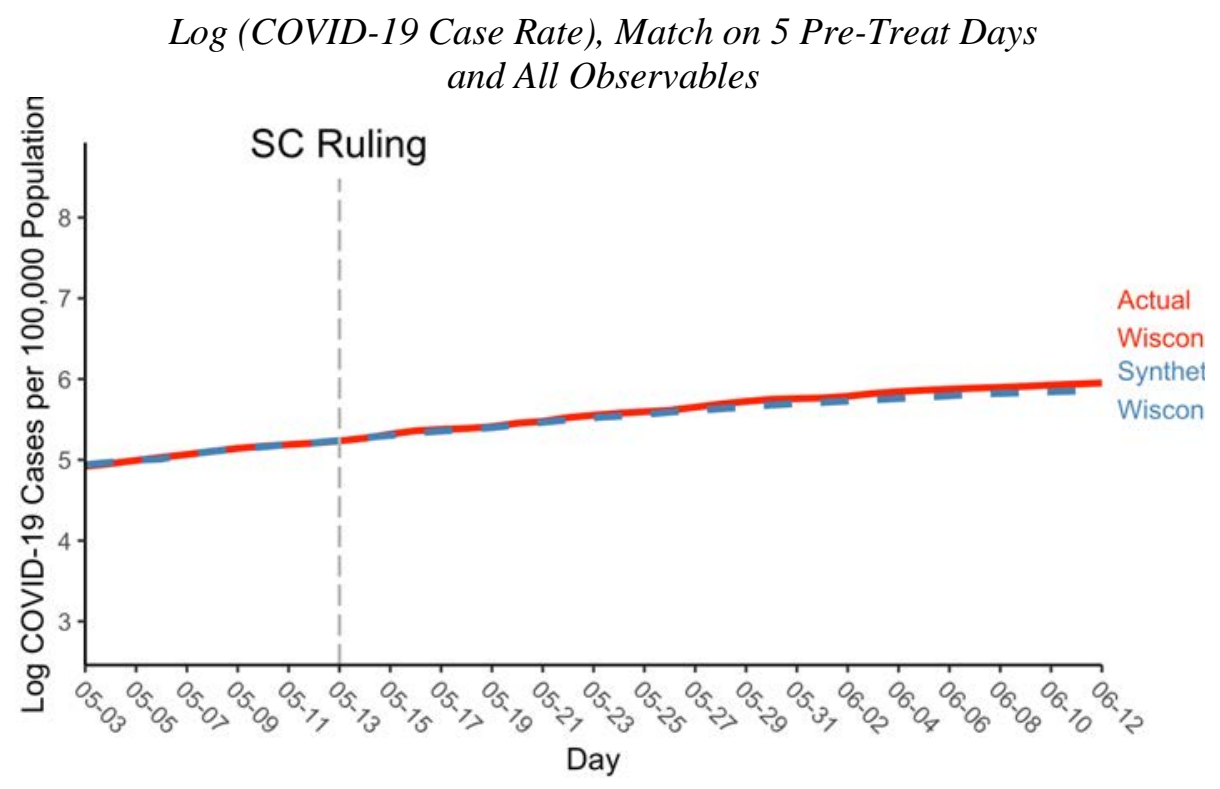




\section{Figure 5. Synthetic Control Estimates of Effect of Wisconsin Supreme Court Abolition of SIPO on COVID-19 Cases Rate Per 100,000 Population in "Bound Wisconsin"}

Panel (a): COVID-19 Case Rate Levels, Three Week Post-Treatment

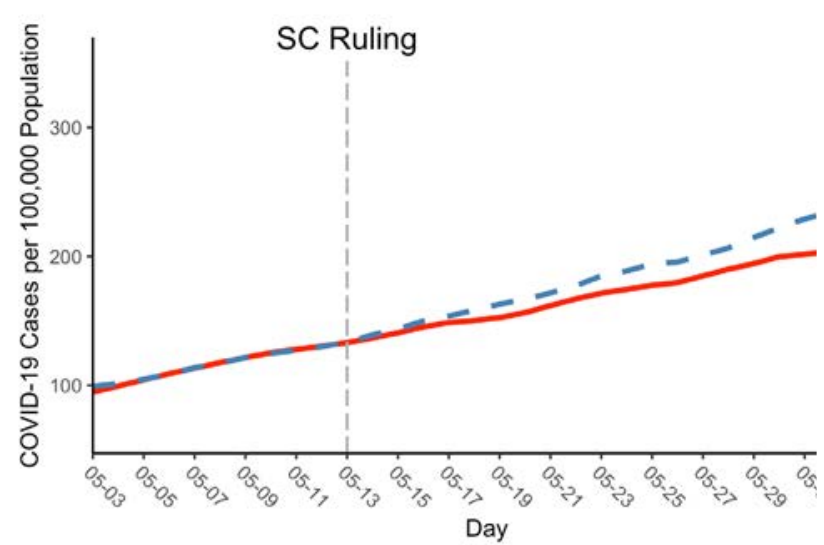

Note: Synthetic WI is comprised of NC (.729), \& OR (.271).

Panel (c): COVID-19 Case Rate Levels, One Month Post-Treatment

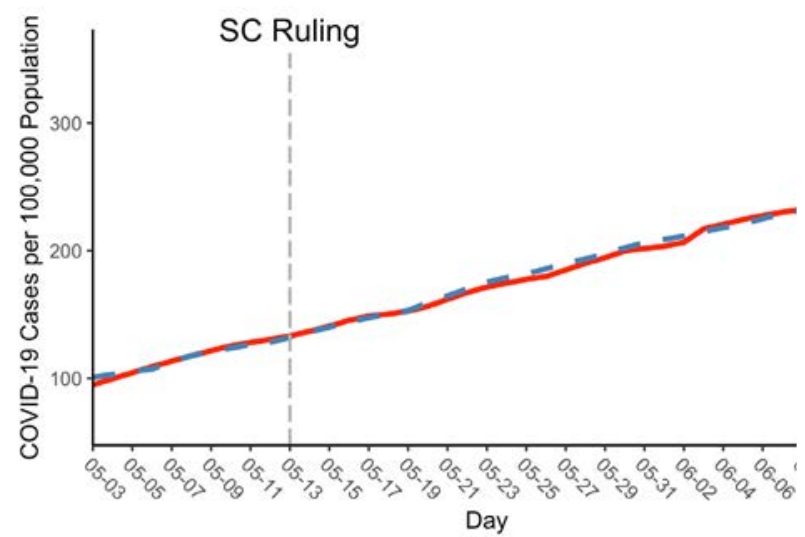

Note: Synthetic WI is comprised of ME. (907), \& VA (.093
Panel (b): Log (COVID-19 Case Rate), Three Week Post-Treatment

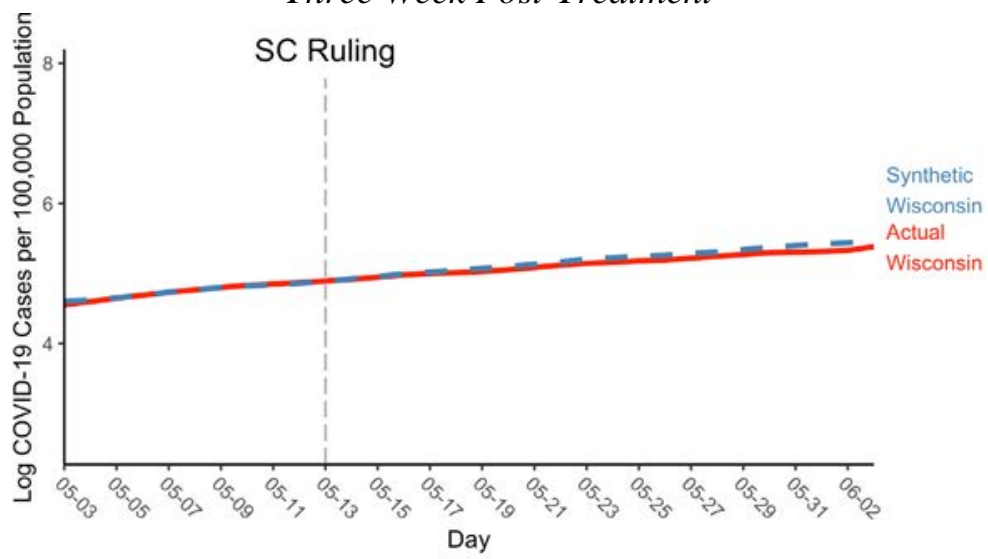

Note: Synthetic WI is comprised of NC (.63), ME (.29), OR (0.067), \& HI (.011).

Panel (d): Log (COVID-19 Case Rate), One Month Post-Treatment

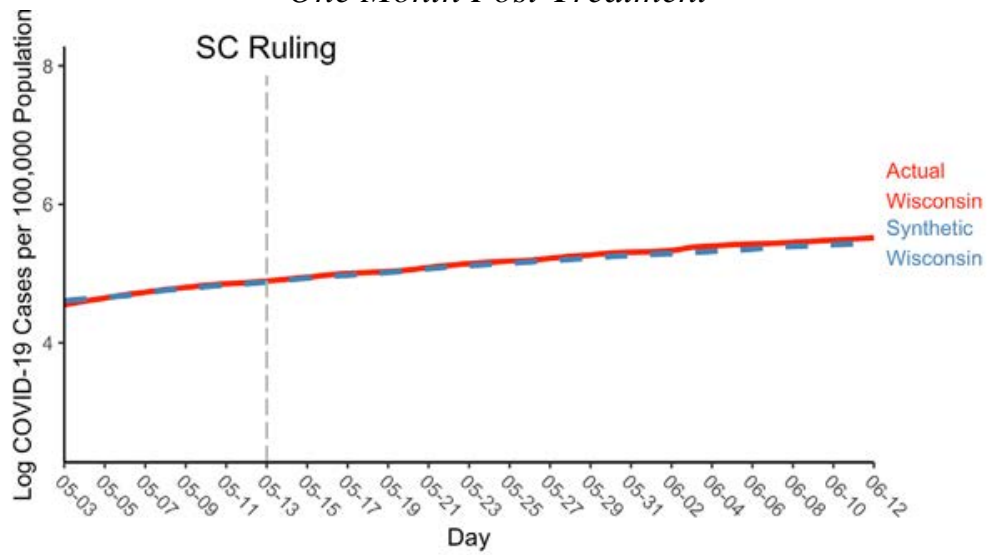

Note: Synthetic WI is comprised of ME (.445), OR (.309), \& VA (.246). 
Figure 6. Synthetic Control Estimates of Effect of Wisconsin Supreme Court Abolition of SIPO

on COVID-19 Case Rate Per 100,000 Population in "Bound Wisconsin” with Above Median Restaurant and Bar Foot Traffic

Panel (a): COVID-19 Case Rate Levels, Three Weeks Post-Treatment

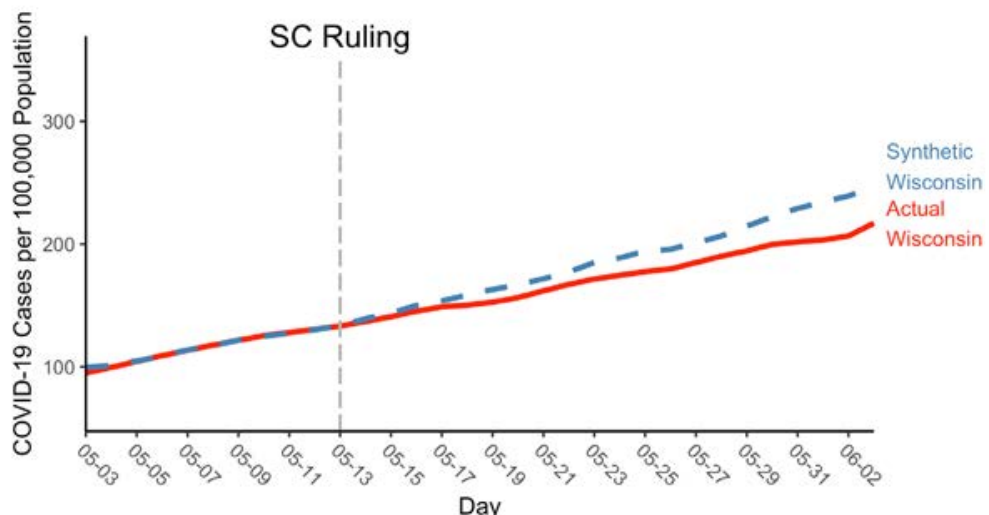

Note: Synthetic WI is comprised of NC (.729), \& OR (.271).

Panel (c): COVID-19 Case Rate Levels, One Month Post-Treatment

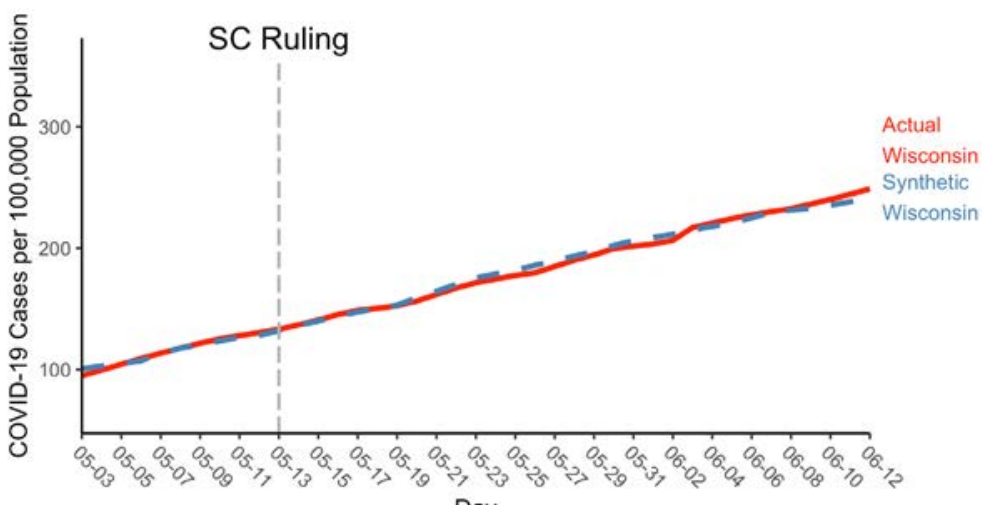

Note: Synthetic WI is comprised of ME. (907), \& VA (.093)
Panel (b): Log (COVID-19 Case Rate), Three Weeks Post-Treatment

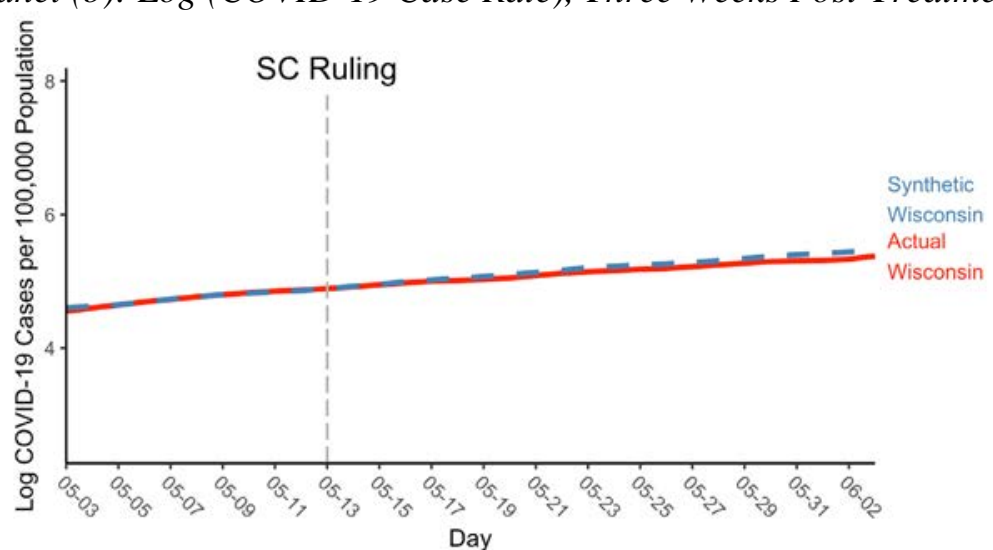

Note: Synthetic WI is comprised of NC (.63), ME (.29), OR (.067) \& HI (.011).

Panel (d): Log (COVID-19 Case Rate), One Month Post-Treatment

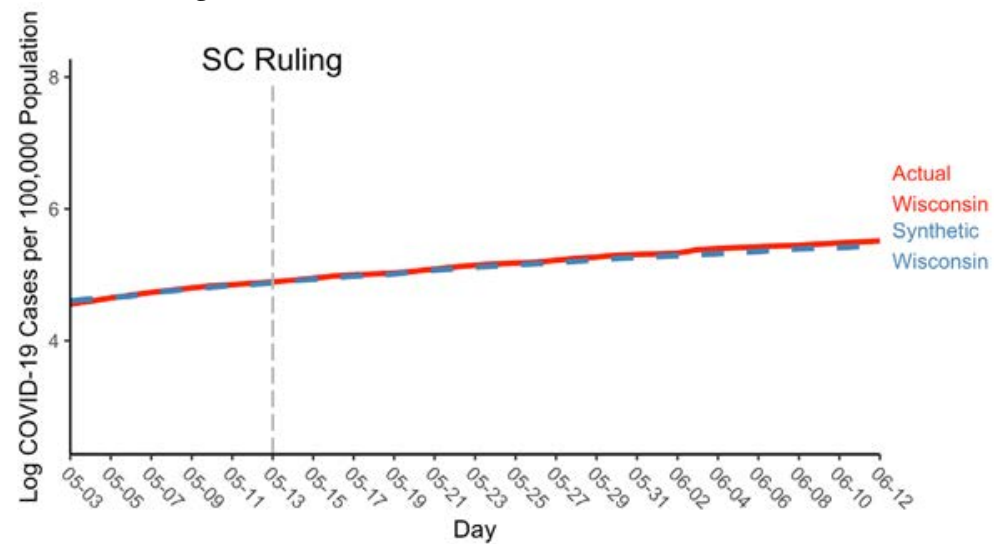

Note: Synthetic WI is comprised of ME (.445), OR (.309), \& VA (.246). 
Figure 7. Synthetic Control Estimates of Effect of Wisconsin Supreme Court Abolition of SIPO on COVID-19 Deaths Rate Per 100,000 Population in Wisconsin

Panel (a): COVID-19 Deaths Rate Levels, One Month Post-Treatment

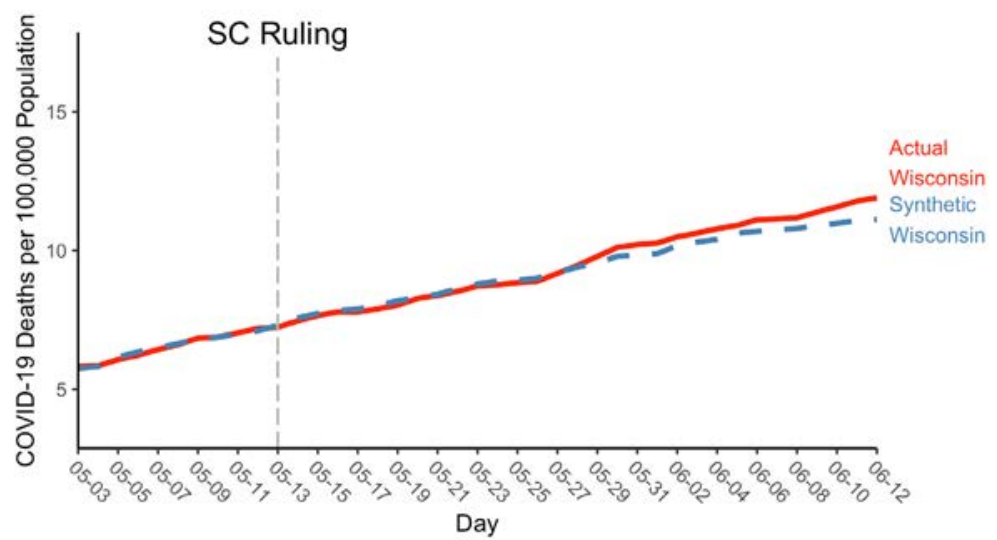

Note: Synthetic WI is comprised of ME (.539), HI (.209) CA (.08) \& PA (.048).

Panel (b): Log (COVID-19 Deaths Rate), One Month Post-Treatment

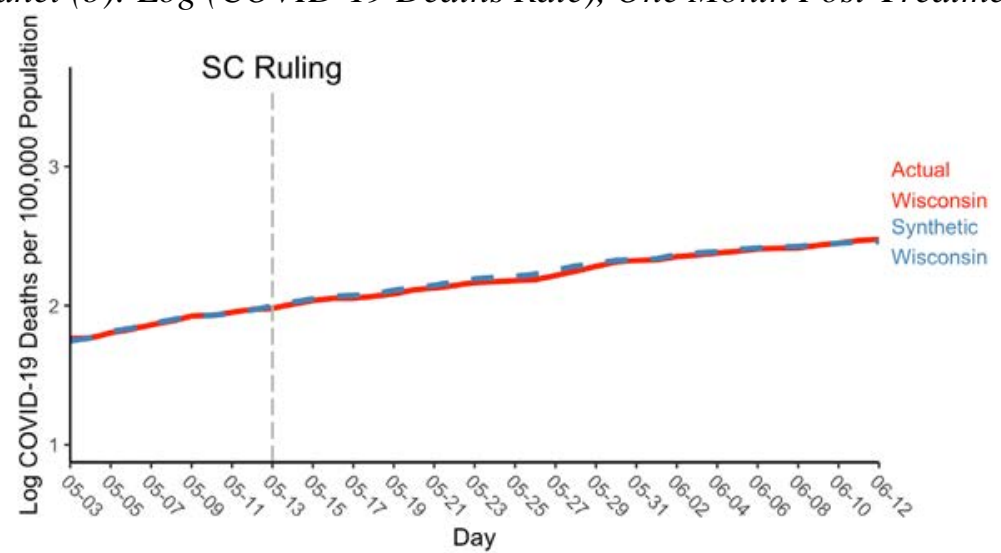

Note: Synthetic WI is comprised of CA (.363), ME (.361), VA (.231), \& MI (.025). 


\section{Table 1. Synthetic Control Estimates of Effect of Wisconsin Supreme Court Abolition of SIPO on Social Distancing}

\begin{tabular}{|c|c|c|c|c|}
\hline & $(1)$ & $(2)$ & (3) & $(4)$ \\
\hline & \multicolumn{4}{|c|}{ Panel I: Percent at Home Full-Time } \\
\hline SIPO & -0.667 & 0.162 & 0.187 & 0.061 \\
\hline P-Value & {$[0.737]$} & [0.842] & [0.789] & [0.842] \\
\hline \multirow[t]{2}{*}{ Pre-Treatment Mean } & 37.51 & 37.51 & 37.51 & 37.51 \\
\hline & \multicolumn{4}{|c|}{ Panel II: Median Hours at Home } \\
\hline SIPO & -0.472 & -0.424 & -0.422 & -0.402 \\
\hline P-Value & {$[0.316]$} & [0.316] & [0.368] & [0.421] \\
\hline \multirow[t]{2}{*}{ Pre-Treatment Mean } & 12.93 & 12.93 & 12.93 & 12.93 \\
\hline & \multicolumn{4}{|c|}{ Panel III: Restaurants or Bars } \\
\hline SIPO & 0.121 & 0.110 & 0.149 & $0.121 *$ \\
\hline \multirow[t]{2}{*}{ P-Value } & [0.368] & [0.368] & [0.211] & [0.053] \\
\hline & \multicolumn{4}{|c|}{ Panel IV: Retail } \\
\hline SIPO & 0.060 & 0.039 & 0.029 & 0.023 \\
\hline P-Value & [0.316] & [0.526] & [0.684] & [0.737] \\
\hline \multicolumn{5}{|l|}{ Matching on Observables } \\
\hline Days Pre-Treat Social Distance & 10 & $5^{\mathrm{a}}$ & 5 & 5 \\
\hline Testing Trend ${ }^{\mathrm{b}}$ & & $\mathrm{Y}$ & $\mathrm{Y}$ & $\mathrm{Y}$ \\
\hline Other Reopening Policies & & & Y & $\mathrm{Y}$ \\
\hline Percent Republican Vote & & & $\mathrm{Y}$ & $\mathrm{Y}$ \\
\hline Pre-Treat COVID-19 Cases ${ }^{\mathrm{C}}$ & & & & $\mathrm{Y}$ \\
\hline Urbanicity & & & & $\mathrm{Y}$ \\
\hline Population Density & & & & Y \\
\hline
\end{tabular}

* Significant at the $10 \%$ level, ** Significant at the $5 \%$ level, *** Significant at the $1 \%$ level

Notes: Estimate is generated using synthetic control methods. Post-treatment period includes three weeks (until 6/2). The matching was based on pre-treatment case rates and observables listed under each column. The permutation-based p-values are calculated via placebo tests and are included in brackets below each point estimate. Donor states included CA, DC, DE, HI, IL, LA, ME, MI, NC, NH, NJ, NM, NY, OH, OR, PA, VA, and WA.

${ }^{a}$ The days of pre-treatment COVID-19 case rate matches include 5/4, 5/6, 5/8, 5/10, 5/12

${ }^{b}$ The days of testing rate matches include $5 / 3,5 / 11,5 / 15,5 / 21,6 / 2$ 


\section{Table 2. Synthetic Control Estimates of Effect of Wisconsin Supreme Court Abolition of SIPO on COVID-19 Cases Per 10,000 Population}

\begin{tabular}{|c|c|c|c|c|}
\hline & $(1)$ & $(2)$ & (3) & (4) \\
\hline & \multicolumn{4}{|c|}{ Panel I: COVID-19 Cases per 100,000 Population } \\
\hline SIPO & -1.621 & -2.415 & -1.287 & -1.229 \\
\hline P-Value & [0.882] & {$[0.824]$} & {$[0.824]$} & [0.882] \\
\hline \multirow[t]{2}{*}{ Pre-Treatment Mean Case Rate } & 161.1 & 161.1 & 161.1 & 161.1 \\
\hline & \multicolumn{4}{|c|}{ Panel II: Log (COVID-19 Cases per 100,000 Population) } \\
\hline SIPO & 0.002 & -0.017 & -0.022 & -0.014 \\
\hline P-Value & [0.895] & [0.632] & [0.737] & {$[0.684]$} \\
\hline \multicolumn{5}{|l|}{ Matching on Observables } \\
\hline Days of Pre-Treatment Cases & 10 & $5^{\mathrm{a}}$ & 5 & 5 \\
\hline Testing Trend $^{\mathrm{b}}$ & & $\mathrm{Y}$ & $\mathrm{Y}$ & $\mathrm{Y}$ \\
\hline Other Reopening Policies & & & Y & $\mathrm{Y}$ \\
\hline Percent Republican Vote & & & $\mathrm{Y}$ & $\mathrm{Y}$ \\
\hline Pre-Treatment Social Distance & & & & $\mathrm{Y}$ \\
\hline Urbanicity & & & & $\mathrm{Y}$ \\
\hline Population Density & & & & $\mathrm{Y}$ \\
\hline
\end{tabular}

* Significant at the $10 \%$ level, ** Significant at the $5 \%$ level, *** Significant at the $1 \%$ level

Notes: Estimate is generated using synthetic control methods. Post-treatment period includes three weeks (until 6/2). The matching was based on pre-treatment case rates and observables listed under each column. The permutation-based p-values are calculated via placebo tests and are included in brackets below each point estimate. Donor states included CA, DC, DE, HI, IL, LA, ME, MI, NC, NH, NJ, NM, NY, OH, OR, PA, VA, and WA.

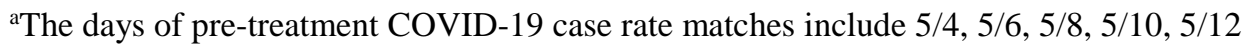

${ }^{\text {b}}$ The days of testing rate matches include $5 / 3,5 / 11,5 / 15,5 / 21,6 / 2$ 
WI Supreme Court SIPO Ruling

Permutation-based [p-value]

Placebo Test $\{$ Wisconsin Rank / \# Donor States + 1\}

WI Supreme Court SIPO Ruling * WI County Fully Bound Permutation-based [p-value]

Placebo Test $\{$ Wisconsin Rank / \# Donor States + 1\}

WI Supreme Court SIPO Ruling * WI County Mitigating Order

Permutation-based [p-value]

Placebo Test \{Wisconsin Rank / \# Donor States + 1\}

WI Supreme Court SIPO Ruling * $\geq 50 \%$ Urbanicity Permutation-based [p-value]

Placebo Test \{Wisconsin Rank / \# Donor States + 1\}

WI Supreme Court SIPO Ruling* < 50\% Urbanicity

Permutation-based [p-value]

Placebo Test $\{$ Wisconsin Rank / \# Donor States + 1\}

WI Supreme Court SIPO Ruling * $\geq 50 \%$ Voted for Trump Permutation-based [p-value]

Placebo Test $\{$ Wisconsin Rank / \# Donor States +1$\}$

WI Supreme Court SIPO Ruling* $<50 \%$ Voted for Trump

Permutation-based [p-value]

Placebo Test $\{$ Wisconsin Rank / \# Donor States + 1\}

Mean of Dependent Variable

\begin{tabular}{|c|c|c|c|c|}
\hline$(1)$ & $(2)$ & (3) & $(4)$ & $(5)$ \\
\hline $\begin{array}{l}\text { \% Stay at } \\
\text { Home Full- } \\
\text { Time }\end{array}$ & $\begin{array}{c}\text { Median } \\
\text { Hours at } \\
\text { Home }\end{array}$ & $\begin{array}{l}\text { Foot Traffic } \\
\text { into Retail }\end{array}$ & $\begin{array}{c}\text { Foot Traffic } \\
\text { into Restaurants } \\
\& \text { Bars }\end{array}$ & Log(Cases) \\
\hline \multicolumn{5}{|c|}{ Panel I: Overall } \\
\hline-0.311 & -0.481 & 0.041 & 0.105 & -0.031 \\
\hline$[.842]$ & {$[.421]$} & {$[.578]$} & {$[.316]$} & [1.000] \\
\hline$\{16 / 19\}$ & $\{8 / 19\}$ & $\{11 / 19\}$ & $\{6 / 19\}$ & $\{19 / 19\}$ \\
\hline \multicolumn{5}{|c|}{ Panel II: Mitigating Local Order } \\
\hline-0.131 & -0.513 & 0.056 & $0.173^{*}$ & -0.017 \\
\hline [1.000] & {$[.388]$} & {$[.500]$} & {$[.056]$} & {$[.944]$} \\
\hline$\{18 / 18\}$ & $\{7 / 18\}$ & $\{9 / 18\}$ & $\{1 / 18\}$ & $\{17 / 18\}$ \\
\hline-0.494 & -0.449 & 0.026 & 0.035 & -0.045 \\
\hline$[.736]$ & {$[.421]$} & {$[.736]$} & {$[.736]$} & {$[.947]$} \\
\hline$\{14 / 19\}$ & $\{8 / 19\}$ & $\{14 / 19\}$ & $\{14 / 19\}$ & $\{18 / 19\}$ \\
\hline \multicolumn{5}{|c|}{ Panel III: County Urbanicity } \\
\hline-0.523 & -0.516 & 0.035 & 0.071 & -0.046 \\
\hline$[.788]$ & {$[.316]$} & {$[.632]$} & {$[.474]$} & {$[.947]$} \\
\hline$\{15 / 19\}$ & $\{6 / 19\}$ & $\{12 / 19\}$ & $\{9 / 19\}$ & $\{18 / 19\}$ \\
\hline 0.466 & -0.352 & 0.065 & 0.227 & 0.027 \\
\hline [.933] & [.532] & {$[.600]$} & [.133] & [.933] \\
\hline$\{14 / 15\}$ & $\{8 / 15\}$ & $\{9 / 15\}$ & $\{2 / 15\}$ & $\{14 / 15\}$ \\
\hline \multicolumn{5}{|c|}{ Panel IV: County \% Voted for Trump } \\
\hline-0.319 & -0.566 & 0.048 & 0.158 & -0.009 \\
\hline$[.882]$ & [.352] & {$[.587]$} & [.118] & [1.000] \\
\hline$\{15 / 17\}$ & $\{6 / 17\}$ & $\{10 / 17\}$ & $\{2 / 17\}$ & $\{17 / 17\}$ \\
\hline-0.303 & -0.392 & 0.034 & 0.049 & -0.054 \\
\hline$[.882]$ & [.352] & {$[.764]$} & [.647] & [.882] \\
\hline$\{15 / 17\}$ & $\{6 / 17\}$ & $\{13 / 17\}$ & $\{11 / 17\}$ & $\{15 / 17\}$ \\
\hline 34.612 & 11.682 & 8.268 & 7.427 & 5.308 \\
\hline
\end{tabular}


* Significant at the $10 \%$ level, ** Significant at the $5 \%$ level, *** Significant at the $1 \%$ level

Notes: Regressions include Wisconsin and each donor state. The weights are generated by multiplying share of state population by the synthetic weights. All estimates include: an indicator for whether retail store and restaurant or bar reopened, an indicator for whether personal or pet care services reopened, an

indicator for whether entertainment and physical activity facilities reopened, log testing, county and day fixed effects. P-values, generated using permutation test, are reported inside brackets and ranking of the treated unit is included in braces. 
Online Appendix Figures and Tables 


\section{Appendix Figure 1. Trends in COVID-19 Cases and Deaths by State}
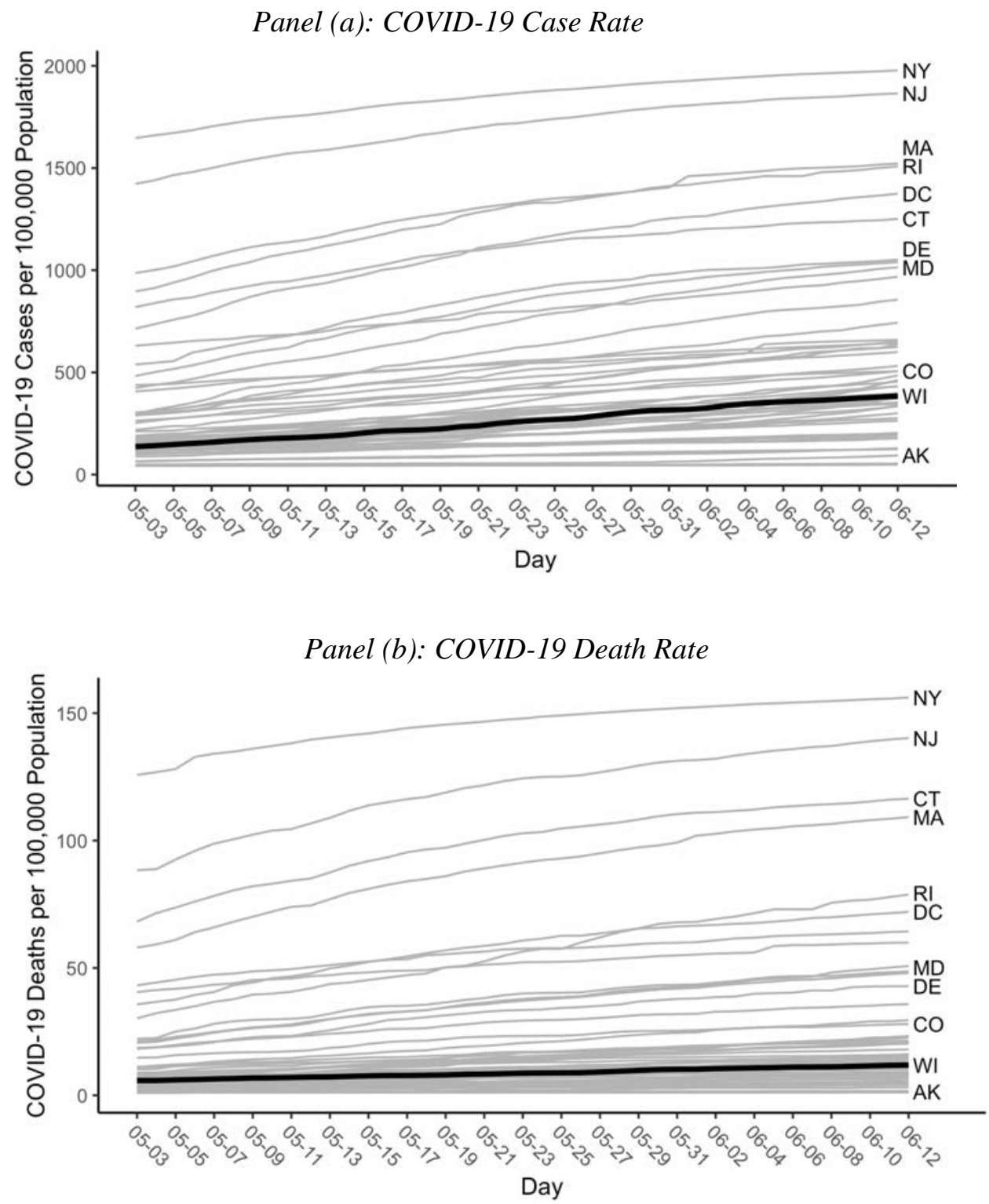


\section{Appendix Figure 2. Placebo Tests for Social Distancing Measures}

Panel (a): Percent at Home Full-Time, Match on All Pre-Treat Days

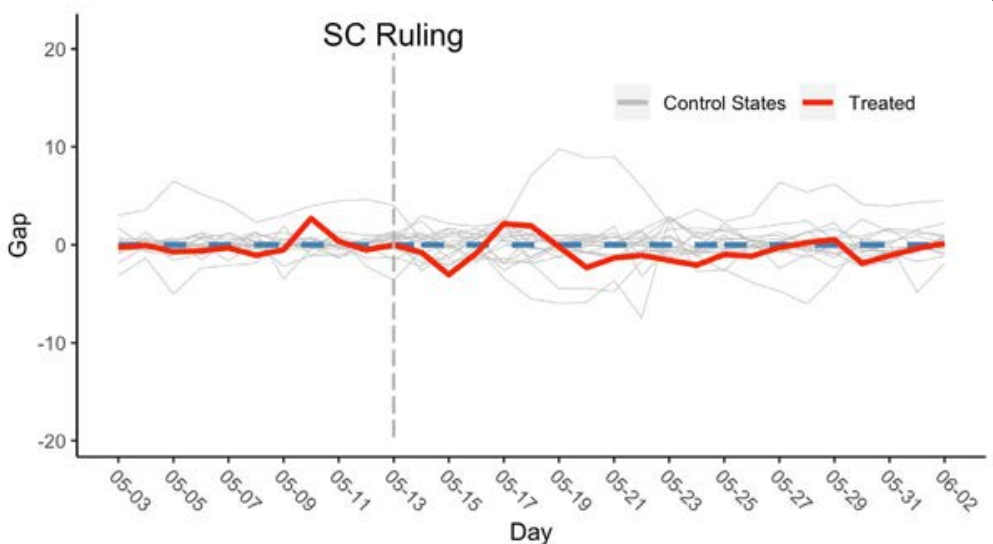

Note: Synthetic WI is comprised of IL (.527), LA (.249), NM (.195), \& MI (.028).

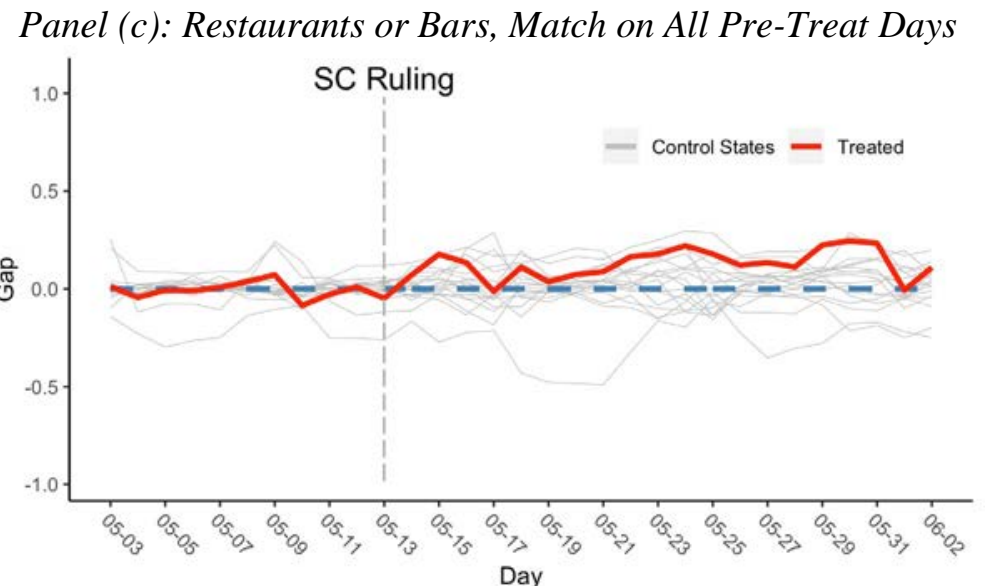

Note: Synthetic WI is comprised of MI (.684), NH (.218), \& NM (.098).
Panel (b): Median Hours at Home, Match on All Pre-Treat Days

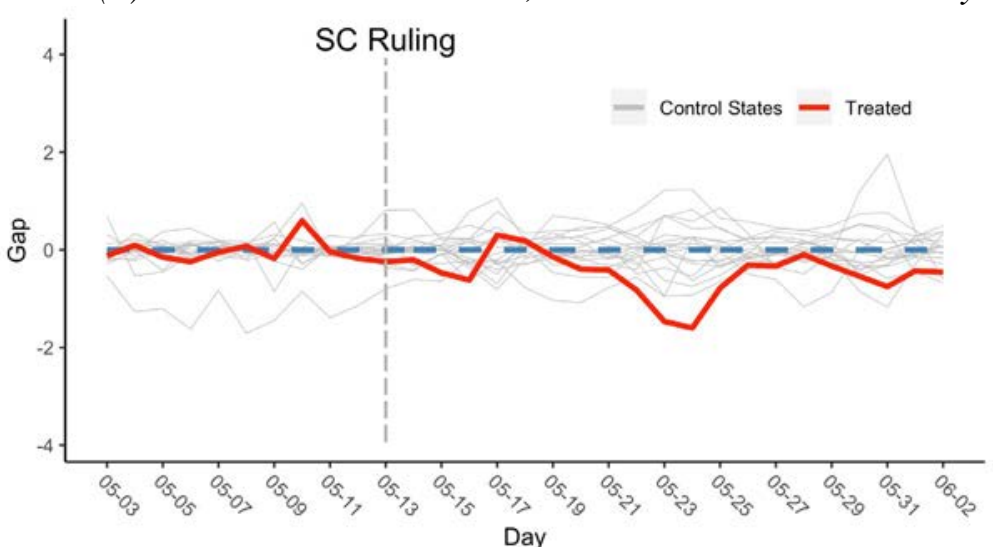

Note: Synthetic WI is comprised of NM (.466), IL (.412), \& OH (.122).

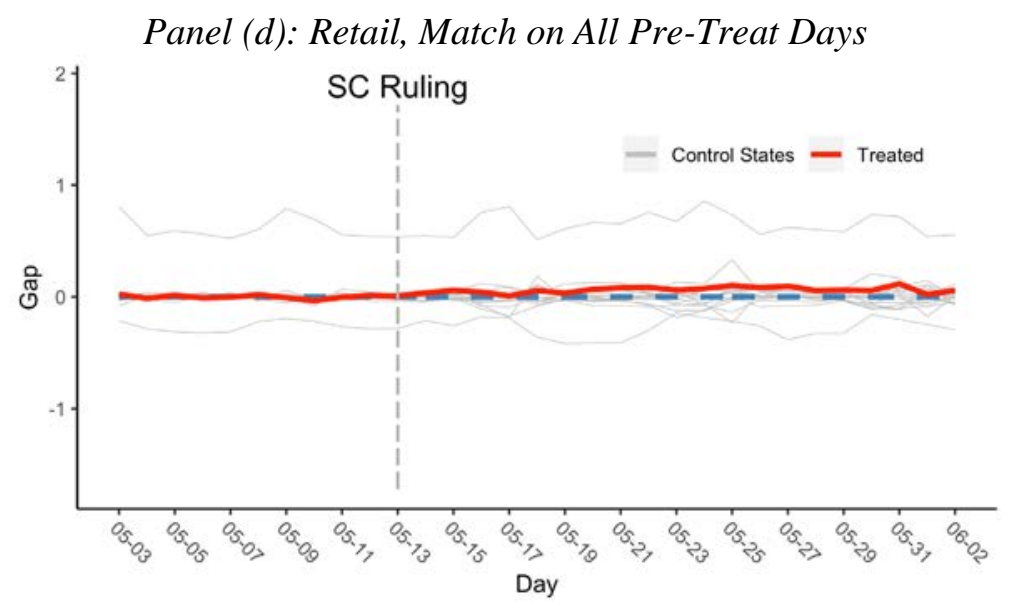

Note: Synthetic WI is comprised of IL (.862), NH (.095), \& MI (.013). 


\section{Appendix Figure 3. Synthetic Control Estimates for Initial Enactment of Wisconsin SIPO Enacted on March 25}

Panel (a): Percent Stay at Home Full-Time

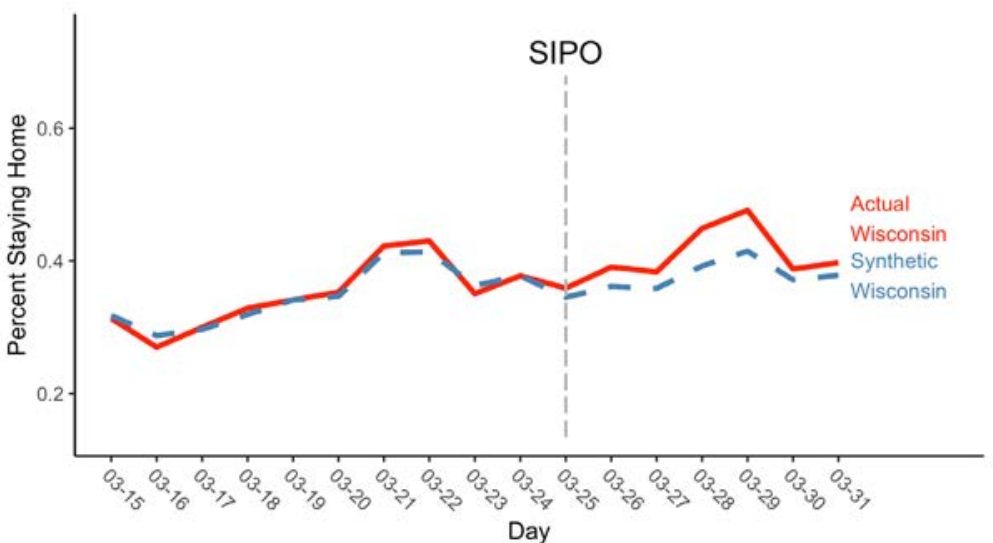

Note: Synthetic WI is comprised of NV (.316), IA (.30), TX (.134), MO (.114), UT (.07), \& PA (.066)

Panel (c): COVID-19 Cases Per 100,000 Population

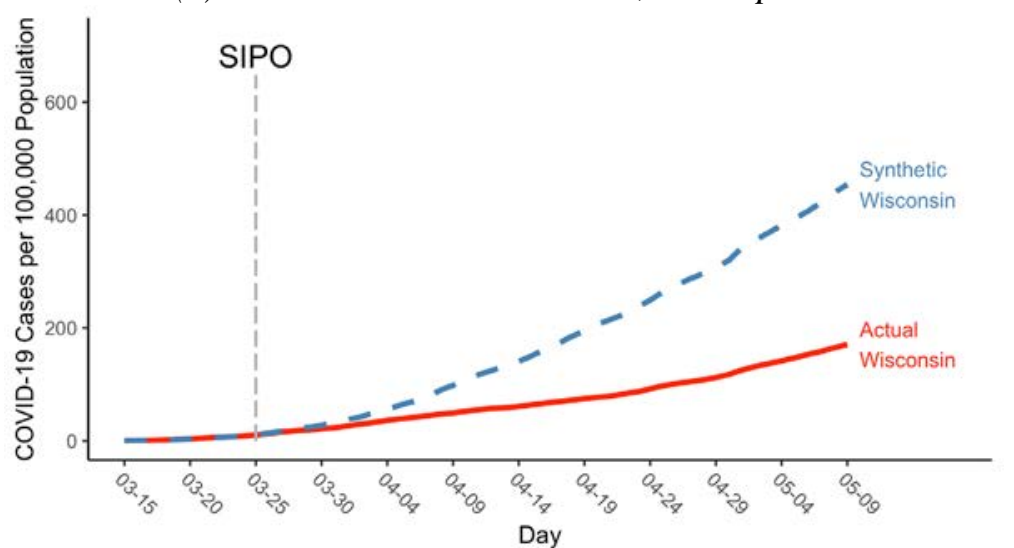

Note: Synthetic WI is comprised of NC (.824), VA (.069), NM (.04) \& CA (.015).
Panel (b): Placebo Tests for \% Staying at Home

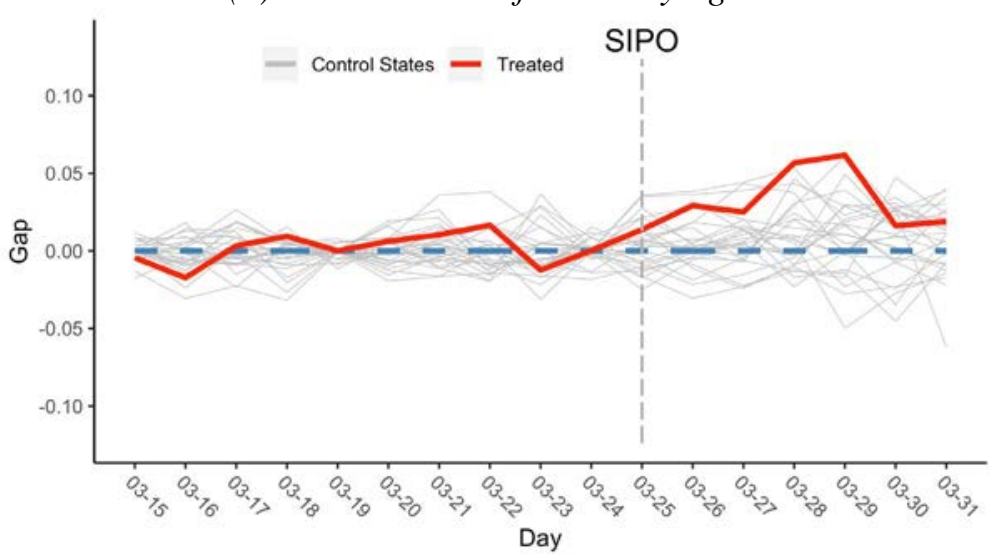

Note: Synthetic WI is comprised of NV (.316), IA (.30), TX (.134), MO (.114), UT (.07), \& PA (.066)

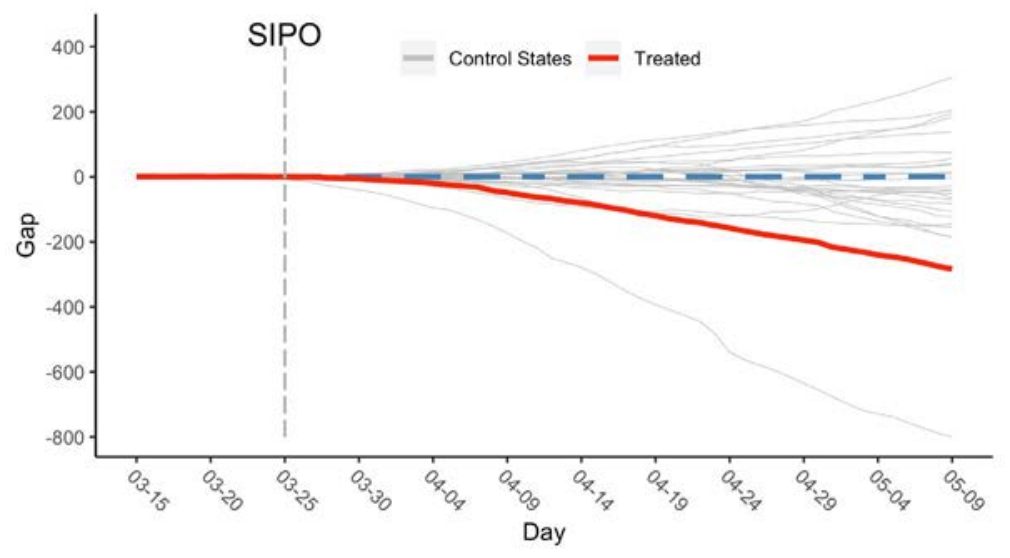

Note: Synthetic WI is comprised of NC (.824), VA (.069), NM (.04) \& CA (.015) 
Appendix Figure 4. Pre- WI Supreme Court Ruling Trends in COVID-19 Cases by WI County Type

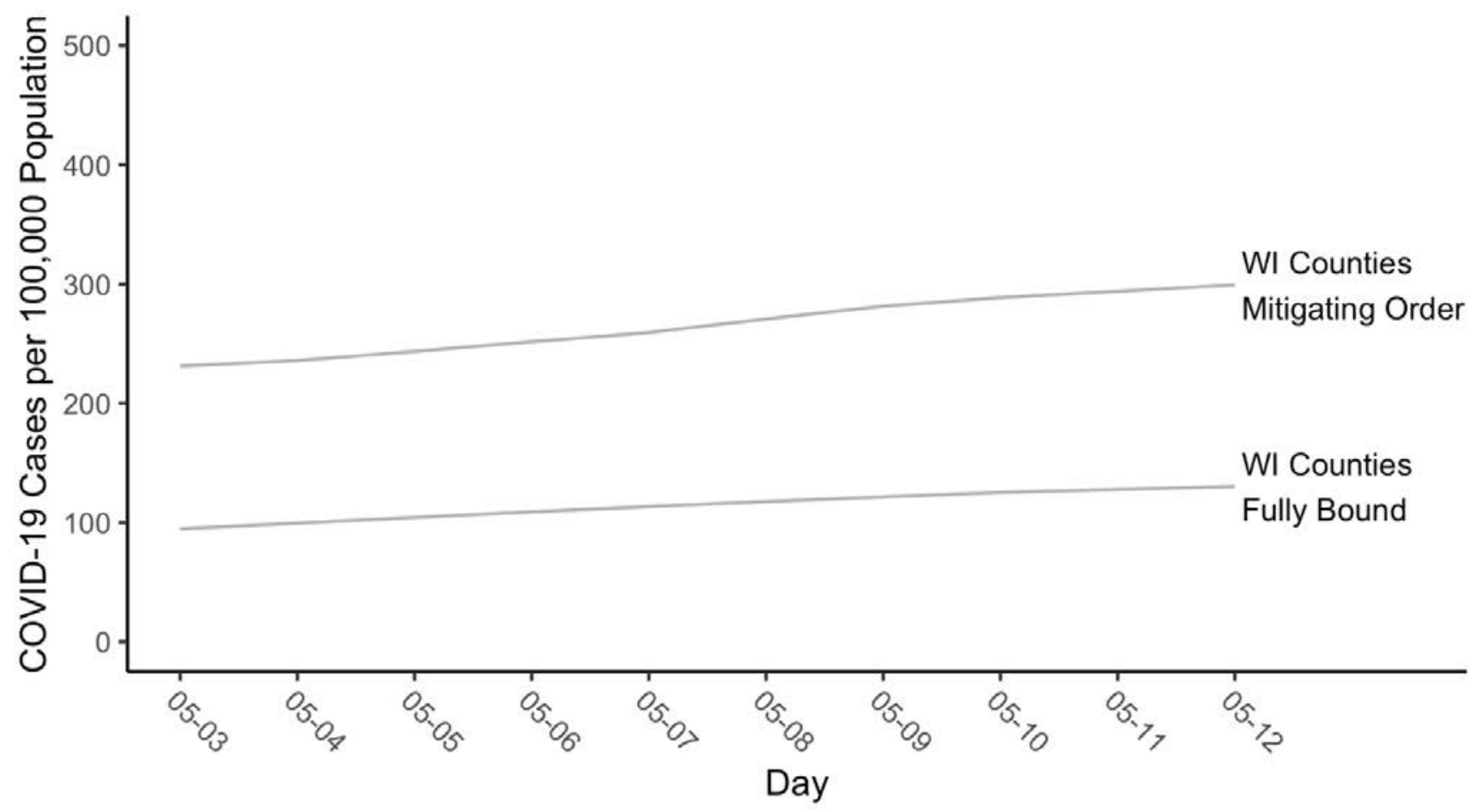


(1)

IL (.527), LA (.249), NM (.195),

MI ( .028)
(2)

OH (.632), $\quad$ OH (.632), $\quad$ OH (.532), IL (.212), IL (.207), ME (.237), ME (.156) ME (.161) IL (.231)

(3)

(4)

Observables for constructing weights:

Days Pre-Treat Social Distance

10

Testing Trend

Other Reopening Policies

Percent Republican Vote

Pre-Treat COVID-19 Cases

Urbanicity

Population Density

$5^{\mathrm{a}}$
$\mathrm{Y}$

$\begin{array}{ll}5 & 5 \\ Y & Y \\ Y & Y \\ Y & Y \\ & Y \\ & Y \\ & Y\end{array}$

Appendix Table 1B. List of Donor States that Received Positive Weights in Table 1 Panel II

Observables for constructing weights:

(1)

NM (.466),
IL (.412),
OH (.122)

(2) NC (.626), OH (.608), IL (.208), ME (.163), NM (.002)
IL (.215), ME (.175), HI (.002)
(4)

NC (.545), IL (.239), $\mathrm{ME}(.208)$, $\mathrm{OH}(.007)$, HI (.001)

Days Pre-Treat Social Distance 10

Testing Trend

Other Reopening Policies

Percent Republican Vote

Pre-Treat COVID-19 Cases

Urbanicity

Population Density

$\begin{array}{ccc}5^{\mathrm{a}} & 5 & 5 \\ \mathrm{Y} & \mathrm{Y} & \mathrm{Y} \\ & \mathrm{Y} & \mathrm{Y} \\ & \mathrm{Y} & \mathrm{Y} \\ & & \mathrm{Y} \\ & & \mathrm{Y} \\ & & \mathrm{Y}\end{array}$


Appendix Table 1C. List of Donor States that Received Positive Weights in Table 1 Panel III

\begin{tabular}{cccc}
$(1)$ & $(2)$ & $(3)$ & $(4)$ \\
\hline & VA (.458), & PA (.495), & MI (.626), \\
MI (.684), & NH (.326), & NC (.153), & NM (.052), \\
NH (.218), & ME (.176), & MI (.091), & LA (.011), \\
NM (.098) & MI (.026) & HI (.012) & ME (.010)
\end{tabular}

Observables for constructing weights:

Days Pre-Treat Social Distance

10

Testing Trend ${ }^{\mathrm{b}}$

Other Reopening Policies

Percent Republican Vote

$\begin{array}{ccc}5^{\mathrm{a}} & 5 & 5 \\ \mathrm{Y} & \mathrm{Y} & \mathrm{Y} \\ & \mathrm{Y} & \mathrm{Y} \\ & \mathrm{Y} & \mathrm{Y} \\ & & \mathrm{Y} \\ & & \mathrm{Y} \\ & & \mathrm{Y}\end{array}$

\section{Appendix Table 1D. List of Donor States that Received Positive Weights in Table 1 Panel IV}

Observables for constructing weights:

Days Pre-Treat Social Distance 10

Testing Trend

(2)

(3)

(4)

\begin{tabular}{cccc}
\hline & & & \\
& & OH $(.298)$, & \\
& OH (.395), & VA $(.277)$, & OH $(.290)$, \\
IL (.862), & VA (.296), & NC (.139), & NC (.239), \\
NH (.095), & IL (.149), & ME (.081), & CA (.212), \\
MI (.013) & ME (.123), & MI (.044), & ME (.099), \\
& NC (.012). & OR (.017), & VA (.011), \\
& OR (.009) & IL (.016), & MI (.009) \\
& & CA (.011)
\end{tabular}

Other Reopening Policies

Percent Republican Vote

Pre-Treat COVID-19 Cases

$5^{\mathrm{a}}$
$\mathrm{Y}$

$\begin{array}{cc}5 & 5 \\ Y & \mathrm{Y} \\ \mathrm{Y} & \mathrm{Y} \\ \mathrm{Y} & \mathrm{Y} \\ & \mathrm{Y} \\ & \mathrm{Y} \\ & \mathrm{Y}\end{array}$


(1)

(2)

(3)

Panel I: COVID-19 Cases per 100,000

NC (.817),

VA $(.071)$

NM (.046),

CA (0.15),

IL (.013)

NC (.869), NC (.817), NC (.817),

IL (.059), CA (.078), CA (.082),

NM (.040), IL (.053), IL (.054),

CA (.029) NM (.050) NM (.045)

Panel II: Log(COVID-19 Cases per 100,000)

\begin{tabular}{cccc}
\hline NC (.711), & & & NC (.753), \\
NM $(.059)$, & NC (.765), & & VA $(.113)$, \\
VA (.055), & VA (.111), & NC (.760), & CA $(.027)$, \\
CA (.032), & CA (.022), & VA (.086), & NH (.016), \\
IL (.020), & IL (.021), & IL (.084), & IL (.013), \\
NH (.019), & NH (.016), & CA (.057) & DE (.012), \\
OH (.018), & DE (.015), & & MI (.012), \\
DE (.014), & MI (.012) & PA (.010) \\
DC (.013), & & & \\
PA (.010) & &
\end{tabular}

Observables for constructing weights:

Days of Pre-Treatment Cases

Testing Trend ${ }^{\mathrm{b}}$

10

$5^{\mathrm{a}}$
$\mathrm{Y}$

Other Reopening Policies

Percent Republican Vote

Pre-Treatment Social Distance

Urbanicity

Population Density

\begin{tabular}{cc}
5 & 5 \\
$Y$ & $\mathrm{Y}$ \\
$\mathrm{Y}$ & $\mathrm{Y}$ \\
$\mathrm{Y}$ & $\mathrm{Y}$ \\
& $\mathrm{Y}$ \\
& $\mathrm{Y}$ \\
& $\mathrm{Y}$ \\
\hline
\end{tabular}




\section{Appendix Table 3. Sensitivity of Estimates to Use of a 14 Day Post-Treatment Period and Donor Pool Comprised of States that had a SIPO in Effect Over Entire Post-Treatment Period or had a SIPO expire on March 22 or Later}

\begin{tabular}{|c|c|c|c|c|}
\hline & $(1)$ & $(2)$ & (3) & (4) \\
\hline & \multicolumn{4}{|c|}{ Panel I: COVID-19 Cases per 100,000 Population } \\
\hline SIPO & -1.637 & -3.269 & -1.754 & -1.229 \\
\hline P-Value & [0.882] & [0.765] & {$[0.706]$} & {$[0.24]$} \\
\hline \multirow[t]{2}{*}{ Pre-Treatment Mean Case Rate } & 161.1 & 161.1 & 161.1 & 161.1 \\
\hline & \multicolumn{4}{|c|}{ Panel II: Log (COVID-19 Cases per 100,000 Population) } \\
\hline SIPO & 0.0001 & -0.021 & -0.019 & 0.001 \\
\hline P-Value & [0.947] & [0.632] & [0.684] & [0.947] \\
\hline \multicolumn{5}{|l|}{ Matching on Observables } \\
\hline Days of Pre-Treatment Cases & 10 & $5^{\mathrm{a}}$ & 5 & 5 \\
\hline Testing Trend ${ }^{\mathrm{b}}$ & & $\mathrm{Y}$ & $\mathrm{Y}$ & $\mathrm{Y}$ \\
\hline Other Reopening Policies & & & Y & $\mathrm{Y}$ \\
\hline Percent Republican Vote & & & $\mathrm{Y}$ & $\mathrm{Y}$ \\
\hline Pre-Treatment Social Distance & & & & $\mathrm{Y}$ \\
\hline Urbanicity & & & & $\mathrm{Y}$ \\
\hline Population Density & & & & $\mathrm{Y}$ \\
\hline
\end{tabular}

* Significant at the $10 \%$ level, ** Significant at the $5 \%$ level, *** Significant at the $1 \%$ level

Notes: Estimate is generated using synthetic control methods. Post-treatment period includes two weeks (until 5/26). The matching was based on pre-treatment case rates and observables listed under each column. The permutation-based p-values are calculated via placebo tests and are included in brackets below each point estimate. Donor states included CA, DC, DE, HI, IL, LA, ME, MI, NC, NH, NJ, NM, NY, OH, OR, PA, VA, and WA.

${ }^{a}$ The days of pre-treatment COVID-19 case rate matches include 5/4, 5/6, 5/8, 5/10, 5/12

${ }^{b}$ The days of testing rate matches include $5 / 3,5 / 11,5 / 15,5 / 21,5 / 26$ 
Appendix Table 4. Sensitivity of Estimates in Table 3 to Controls for State-Specific Linear Time Trend

WI Supreme Court SIPO Ruling

Permutation-based [p-value]

Placebo Test \{Wisconsin Rank / \# Donor States + 1\}

WI Supreme Court SIPO Ruling * WI County Fully Bound Permutation-based [p-value]

Placebo Test $\{$ Wisconsin Rank / \# Donor States +1$\}$

WI Supreme Court SIPO Ruling * WI County Mitigating Order

Permutation-based [p-value]

Placebo Test \{Wisconsin Rank / \# Donor States + 1\}

WI Supreme Court SIPO Ruling * WI County w/o Current Order Permutation-based [p-value]

Placebo Test $\{$ Wisconsin Rank / \# Donor States + 1\}

WI Supreme Court SIPO Ruling * WI County with Current Order Permutation-based [p-value]

Placebo Test $\{$ Wisconsin Rank / \# Donor States +1$\}$

WI Supreme Court SIPO Ruling * $\geq 50 \%$ Urbanicity

Permutation-based [p-value]

Placebo Test $\{$ Wisconsin Rank / \# Donor States + 1\}

WI Supreme Court SIPO Ruling* $<50 \%$ Urbanicity

Permutation-based [p-value]

Placebo Test $\{$ Wisconsin Rank / \# Donor States + 1\}

\begin{tabular}{ccccc}
$(1)$ & $(2)$ & $(3)$ & $(4)$ & $(5)$ \\
$\begin{array}{c}\text { \% Staying } \\
\text { at Home }\end{array}$ & $\begin{array}{c}\text { Median } \\
\text { Hours at } \\
\text { Home }\end{array}$ & $\begin{array}{c}\text { Foot } \\
\text { Traffic } \\
\text { into Retail }\end{array}$ & $\begin{array}{c}\text { Foot Traffic into } \\
\text { Restaurants \& } \\
\text { Bars }\end{array}$ & Log(Cases) \\
\hline \multicolumn{5}{c}{ Panel I: Overall } \\
\hline 0.639 & -0.056 & -0.016 & 0.073 & 0.007 \\
{$[.684]$} & {$[.894]$} & {$[.842]$} & {$[.316]$} & {$[.894]$} \\
$\{13 / 19\}$ & $\{17 / 19\}$ & $\{16 / 19\}$ & $\{6 / 19\}$ & $\{17 / 19\}$
\end{tabular}

\begin{tabular}{ccccc}
\hline \multicolumn{5}{c}{ Panel II: Mitigating Local Order } \\
\hline 0.819 & -0.087 & -0.001 & 0.141 & 0.021 \\
{$[.611]$} & {$[.777]$} & {$[1.000]$} & {$[.111]$} & {$[.500]$} \\
$\{11 / 18\}$ & $\{14 / 18\}$ & $\{18 / 18\}$ & $\{2 / 18\}$ & $\{9 / 18\}$ \\
0.456 & -0.023 & -0.031 & 0.003 & -0.007 \\
{$[.842]$} & {$[.894]$} & {$[1.000]$} & {$[.947]$} & {$[.684]$} \\
$\{16 / 19\}$ & $\{17 / 19\}$ & $\{19 / 19\}$ & $\{18 / 19\}$ & $\{13 / 19\}$
\end{tabular}

\begin{tabular}{ccccc}
\hline \multicolumn{5}{c}{ Panel III: Current Local Order } \\
\hline 0.450 & 0.053 & -0.039 & -0.045 & -0.055 \\
{$[.842]$} & {$[.894]$} & {$[.421]$} & {$[.578]$} & {$[.210]$} \\
$\{16 / 19\}$ & $\{17 / 19\}$ & $\{8 / 19\}$ & $\{11 / 19\}$ & $\{4 / 18\}$ \\
0.705 & -0.093 & -0.009 & 0.114 & 0.029 \\
{$[.666]$} & {$[.722]$} & {$[.944]$} & {$[.166]$} & {$[.388]$} \\
$\{12 / 18\}$ & $\{13 / 18\}$ & $\{17 / 18\}$ & $\{3 / 18\}$ & $\{7 / 18\}$
\end{tabular}

\begin{tabular}{ccccc}
\hline \multicolumn{5}{c}{ Panel IV: County Urbanicity } \\
\hline 0.427 & -0.091 & -0.023 & 0.039 & -0.008 \\
{$[.842]$} & {$[.684]$} & {$[.632]$} & {$[.578]$} & {$[.894]$} \\
$\{16 / 19\}$ & $\{13 / 19\}$ & $\{12 / 19\}$ & $\{11 / 19\}$ & $\{17 / 19\}$ \\
1.416 & 0.074 & 0.008 & $0.195^{*}$ & 0.065 \\
{$[.400]$} & {$[1.000]$} & {$[.866]$} & {$[.067]$} & {$[.266]$} \\
$\{6 / 15\}$ & $\{15 / 15\}$ & $\{13 / 15\}$ & $\{1 / 15\}$ & $\{4 / 15\}$ \\
\hline
\end{tabular}




\begin{tabular}{|c|c|c|c|c|}
\hline (1) & (2) & (3) & (4) & (5) \\
\hline $\begin{array}{l}\% \text { Staying } \\
\text { at Home }\end{array}$ & $\begin{array}{l}\text { Median } \\
\text { Hours at } \\
\text { Home }\end{array}$ & $\begin{array}{c}\text { Foot } \\
\text { Traffic } \\
\text { into Retail }\end{array}$ & $\begin{array}{c}\text { Foot Traffic into } \\
\text { Restaurants \& } \\
\text { Bars }\end{array}$ & Log(Cases) \\
\hline
\end{tabular}

WI Supreme Court SIPO Ruling * $\geq 75$ people per sq. mi Permutation-based [p-value]

Placebo Test $\{$ Wisconsin Rank / \# Donor States +1$\}$

WI Supreme Court SIPO Ruling* $<75$ people per sq. mi

Permutation-based [p-value]

Placebo Test $\{$ Wisconsin Rank / \# Donor States + 1\}

WI Supreme Court SIPO Ruling * $\geq 50 \%$ Voted for Trump Permutation-based [p-value]

Placebo Test $\{$ Wisconsin Rank / \# Donor States + 1\}

WI Supreme Court SIPO Ruling* $<50 \%$ Voted for Trump

Permutation-based [p-value]

Placebo Test \{Wisconsin Rank / \# Donor States + 1\}

\begin{tabular}{ccccc}
\hline \multicolumn{5}{c}{ Panel V: County Population Density } \\
\hline 0.381 & -0.096 & -0.024 & 0.033 & 0.005 \\
{$[.894]$} & {$[.632]$} & {$[.788]$} & {$[.578]$} & {$[1.000]$} \\
$\{17 / 19\}$ & $\{12 / 19\}$ & $\{15 / 19\}$ & $\{11 / 19\}$ & $\{19 / 19\}$ \\
1.510 & 0.082 & 0.009 & $0.206^{*}$ & 0.014 \\
{$[.375]$} & {$[1.000]$} & {$[1.000]$} & {$[.063]$} & {$[.875]$} \\
$\{6 / 16\}$ & $\{16 / 16\}$ & $\{16 / 16\}$ & $\{1 / 16\}$ & $\{14 / 16\}$
\end{tabular}

\begin{tabular}{ccccc}
\hline \multicolumn{5}{c}{ Panel VI: County \% Voted for Trump } \\
\hline 0.631 & -0.140 & -0.010 & 0.126 & 0.029 \\
{$[.705]$} & {$[.764]$} & {$[.824]$} & {$[.175]$} & {$[.412]$} \\
$\{12 / 17\}$ & $\{13 / 17\}$ & $\{14 / 17\}$ & $\{3 / 17\}$ & $\{7 / 17\}$ \\
0.648 & 0.033 & -0.023 & 0.017 & -0.016 \\
{$[.647]$} & {$[.940]$} & {$[.764]$} & {$[.824]$} & {$[.764]$} \\
$\{11 / 17\}$ & $\{16 / 17\}$ & $\{13 / 17\}$ & $\{14 / 17\}$ & $\{13 / 17\}$ \\
& & & & \\
34.612 & 11.682 & 8.268 & 7.427 & 5.308 \\
30721 & 30721 & 30721 & 30721 & 29939
\end{tabular}

Mean of Dependent Variable

30721

30721

3072

30721

29939

* Significant at the $10 \%$ level, ** Significant at the $5 \%$ level, *** Significant at the $1 \%$ level

Notes: Regressions include Wisconsin and each donor state. The weights are generated by multiplying share of state population by the synthetic weights. All estimates include: an indicator for whether retail store and restaurant or bar reopened, an indicator for whether personal or pet care services reopened, an indicator for whether entertainment and physical activity facilities reopened, log testing, state-specific linear time trends, county and day fixed effects. P-values, generated using permutation test, are reported inside brackets. 


\section{Appendix Table 5. Sensitivity of Heterogeneity Estimates to Classification of Local Order and Population Sensitivity}

\begin{tabular}{|c|c|c|c|c|}
\hline (1) & (2) & (3) & (4) & (5) \\
\hline $\begin{array}{l}\% \text { Stay at } \\
\text { Home } \\
\text { Full-Time }\end{array}$ & $\begin{array}{c}\text { Median } \\
\text { Hours at } \\
\text { Home }\end{array}$ & $\begin{array}{c}\text { Foot } \\
\text { Traffic } \\
\text { into Retail }\end{array}$ & $\begin{array}{c}\text { Foot Traffic into } \\
\text { Restaurants \& } \\
\text { Bars }\end{array}$ & Log(Cases) \\
\hline \multicolumn{5}{|c|}{ Panel I: Mitigating Local Order } \\
\hline-0.500 & -0.373 & 0.019 & -0.013 & -0.093 \\
\hline [.833] & [.474] & [.736] & [.894] & [1.000] \\
\hline$\{15 / 19\}$ & $\{9 / 19\}$ & $\{14 / 19\}$ & $\{17 / 19\}$ & $\{18 / 18\}$ \\
\hline-0.245 & -0.519 & 0.049 & 0.146 & -0.009 \\
\hline$[.833]$ & [.388] & [.500] & [.222] & {$[.578]$} \\
\hline$\{15 / 18\}$ & $\{7 / 18\}$ & $\{9 / 18\}$ & $\{4 / 18\}$ & $\{11 / 18\}$ \\
\hline \multicolumn{5}{|c|}{ Panel II: County Population Density } \\
\hline-0.569 & -0.522 & 0.034 & 0.065 & -0.033 \\
\hline$[.736]$ & [.316] & {$[.578]$} & {$[.526]$} & [.947] \\
\hline$\{14 / 19\}$ & $\{6 / 19\}$ & $\{11 / 19\}$ & $\{10 / 19\}$ & $\{18 / 19\}$ \\
\hline 0.560 & -0.344 & 0.067 & $0.238 *$ & -0.024 \\
\hline$[.813]$ & [.563] & [.563] & [.063] & {$[.875]$} \\
\hline$\{13 / 16\}$ & $\{9 / 16\}$ & $\{9 / 16\}$ & $\{1 / 16\}$ & $\{14 / 16\}$ \\
\hline 34.612 & 11.682 & 8.268 & 7.427 & 5.308 \\
\hline 30721 & 30721 & 30721 & 30721 & 29939 \\
\hline
\end{tabular}

WI Supreme Court SIPO Ruling * WI County w/o Current Order Permutation-based [p-value]

Placebo Test \{Wisconsin Rank / \# Donor States + 1\}

WI Supreme Court SIPO Ruling * WI County with Current Order

Permutation-based [p-value]

Placebo Test \{Wisconsin Rank / \# Donor States + 1\}

WI Supreme Court SIPO Ruling * $\geq 75$ people per sq. mi

Permutation-based [p-value]

Placebo Test \{Wisconsin Rank / \# Donor States + 1\}

WI Supreme Court SIPO Ruling* $<75$ people per sq. mi

Permutation-based [p-value]

Placebo Test $\{$ Wisconsin Rank / \# Donor States + 1\}

30721

30721

* Significant at the $10 \%$ level, ** Significant at the $5 \%$ level, *** Significant at the $1 \%$ level

Notes: Regressions include Wisconsin and each donor state. The weights are generated by multiplying share of state population by the synthetic weights. All estimates include: an indicator for whether retail store and restaurant or bar reopened, an indicator for whether personal or pet care services reopened, an indicator for whether entertainment and physical activity facilities reopened, log testing, county and day fixed effects. P-values, generated using permutation test, are reported inside brackets. 


\section{Appendix Table 6. Synthetic Control Estimates of Effect of Wisconsin Supreme Court Abolition of SIPO on Social Distancing for "Bound Wisconsin"}

\begin{tabular}{|c|c|c|c|c|}
\hline & $(1)$ & $(2)$ & (3) & $(4)$ \\
\hline & \multicolumn{4}{|c|}{ Panel I: Percent at Home Full-Time } \\
\hline SIPO & -0.748 & -0.571 & -0.102 & -0.104 \\
\hline P-Value & {$[0.737]$} & {$[0.737]$} & [0.684] & [0.632] \\
\hline \multirow[t]{2}{*}{ Pre-Treatment Mean } & 35.94 & 35.94 & 35.94 & 35.94 \\
\hline & \multicolumn{4}{|c|}{ Panel II: Median Hours at Home } \\
\hline SIPO & -0.528 & -0.476 & -0.492 & -0.515 \\
\hline P-Value & [0.368] & [0.211] & {$[0.211]$} & [0.211] \\
\hline \multirow[t]{2}{*}{ Pre-Treatment Mean } & 12.81 & 12.81 & 12.81 & 12.81 \\
\hline & \multicolumn{4}{|c|}{ Panel III: Restaurants or Bars } \\
\hline SIPO & $0.196^{*}$ & 0.189 & $0.207^{*}$ & 0.185 \\
\hline \multirow[t]{2}{*}{ P-Value } & [0.053] & [0.105] & {$[0.053]$} & {$[0.263]$} \\
\hline & \multicolumn{4}{|c|}{ Panel IV: Retail } \\
\hline SIPO & $0.069 *$ & 0.036 & 0.061 & 0.042 \\
\hline P-Value & [0.053] & {$[0.421]$} & [0.316] & [0.368] \\
\hline \multicolumn{5}{|l|}{ Matching on Observables } \\
\hline Days Pre-Treat Social Distance & 10 & $5^{\mathrm{a}}$ & 5 & 5 \\
\hline Testing Trend ${ }^{\mathrm{b}}$ & & $\mathrm{Y}$ & $\mathrm{Y}$ & $\mathrm{Y}$ \\
\hline Other Reopening Policies & & & $\mathrm{Y}$ & Y \\
\hline Percent Republican Vote & & & $\mathrm{Y}$ & $\mathrm{Y}$ \\
\hline Pre-Treat COVID-19 Cases ${ }^{\mathrm{C}}$ & & & & $\mathrm{Y}$ \\
\hline Urbanicity & & & & $\mathrm{Y}$ \\
\hline Population Density & & & & $\mathrm{Y}$ \\
\hline
\end{tabular}

* Significant at the $10 \%$ level, ** Significant at the $5 \%$ level, *** Significant at the $1 \%$ level

Notes: Estimate is generated using synthetic control methods. Post-treatment period includes three weeks (until 6/2). The matching was based on pre-treatment case rates and observables listed under each column. The permutation-based pvalues are calculated via placebo tests and are included in brackets below each point estimate. Donor states included CA, DC, DE, HI, IL, LA, ME, MI, NC, NH, NJ, NM, NY, OH, OR, PA, VA, and WA.

${ }^{a}$ The days of pre-treatment COVID-19 case rate matches include 5/4, 5/6, 5/8, 5/10, 5/12

${ }^{\mathrm{b}}$ The days of testing rate matches include $5 / 3,5 / 11,5 / 15,5 / 21,6 / 2$ 


\section{Appendix Table 7. Synthetic Control Estimates of Effect of Wisconsin Supreme Court Abolition of SIPO on COVID-19 Cases Per 10,000 Population for "Bound Wisconsin"}

\begin{tabular}{|c|c|c|c|c|}
\hline & $(1)$ & $(2)$ & (3) & (4) \\
\hline & \multicolumn{4}{|c|}{ Panel I: COVID-19 Cases per 100,000 Population } \\
\hline SIPO & -12.186 & -14.11 & -14.244 & -1.229 \\
\hline P-Value & [0.647] & [0.529] & [0.529] & [0.882] \\
\hline \multirow[t]{2}{*}{ Pre-Treatment Mean Case Rate } & 114.41 & 114.41 & 114.41 & 114.41 \\
\hline & \multicolumn{4}{|c|}{ Panel II: Log (COVID-19 Cases per 100,000 Population) } \\
\hline SIPO & -0.036 & -0.052 & -0.050 & -0.014 \\
\hline P-Value & [0.842] & [0.632] & [0.737] & {$[0.684]$} \\
\hline \multicolumn{5}{|l|}{ Matching on Observables } \\
\hline Days of Pre-Treatment Cases & 10 & $5^{\mathrm{a}}$ & 5 & 5 \\
\hline Testing Trend ${ }^{\mathrm{b}}$ & & $\mathrm{Y}$ & $\mathrm{Y}$ & $\mathrm{Y}$ \\
\hline Other Reopening Policies & & & Y & $\mathrm{Y}$ \\
\hline Percent Republican Vote & & & $\mathrm{Y}$ & $\mathrm{Y}$ \\
\hline Pre-Treatment Social Distance & & & & $\mathrm{Y}$ \\
\hline Urbanicity & & & & $\mathrm{Y}$ \\
\hline Population Density & & & & $\mathrm{Y}$ \\
\hline
\end{tabular}

* Significant at the $10 \%$ level, ** Significant at the $5 \%$ level, *** Significant at the $1 \%$ level

Notes: Estimate is generated using synthetic control methods. Post-treatment period includes three weeks (until 6/2). The matching was based on pre-treatment case rates and observables listed under each column. The permutation-based p-values are calculated via placebo tests and are included in brackets below each point estimate. Donor states included CA, DC, DE, HI, IL, LA, ME, MI, NC, NH, NJ, NM, NY, OH, OR, PA, VA, and WA.

aThe days of pre-treatment COVID-19 case matches include 5/4, 5/6, 5/8, 5/10, 5/12

${ }^{\text {b}}$ The days of testing rate matches include $5 / 3,5 / 11,5 / 15,5 / 21,6 / 2$ 